\title{
Restrições socioambientais ao uso da terra e seu estado de antropização na UGRH do Paranapanema: subsídios à gestão territorial
}

\author{
Socio-environmental restrictions on land use and its \\ anthropization level in the Paranapanema UGRH: subsidies \\ to territorial management
}

Alexei Nowatzki ${ }^{1}$ (D) Jhenifer Priscila Borges do Couto $^{1}$, Eduardo Vedor de Paula ${ }^{1}$ (D), Cristovão Vicente Scapulatempo Fernandes ${ }^{1}$ (D)

${ }^{1}$ Universidade Federal do Paraná - UFPR, Curitiba, PR, Brasil. E-mail: nowatzki.a@gmail.com, jhenifer2504@gmail.com,edugeo@ufpr.br, cris.dhs@ufpr.br

\begin{abstract}
Como citar: Nowatzki, A., Couto, J. P. B., Paula, E. V., \& Fernandes, C. V. S. (2021). Restrições socioambientais ao uso da terra e seu estado de antropização na UGRH do Paranapanema: subsídios à gestão territorial. Revista de Gestão de Água da América Latina, 18, e15. https://doi.org/10.21168/rega.v18e15
\end{abstract}

RESUMO: 0 planejamento e a gestão territorial são processos baseados na organização do espaço geográfico, que foi se consolidando por meio de pressupostos e regras comuns que viabilizaram a vivência em sociedade. Através de diversos mecanismos legais é possível determinar áreas com algum tipo de restrição socioambiental ao uso da terra. 0 presente estudo propõe-se a espacializar de uma forma integrada diferentes tipos de áreas restritivas dentro da Unidade de Gestão de Recursos Hídricos (UGRH) do Paranapanema, sendo elas as Áreas de Preservação Permanente (APPs), Unidades de Conservação (UCs), Áreas Prioritárias para Conservação da Biodiversidade Brasileira, Terras Indígenas, Tombamento Paisagístico Cultural, Mananciais e Assentamentos. A partir da integração dessas camadas de informações, por meio da álgebra de mapas, foi possível determinar até seis classes diferentes de restrições em uma mesma unidade de área. Foi realizada ainda a avaliação do percentual de antropização (sobretudo áreas com atividades agrícolas) de cada área restritiva mapeada a partir de dados de uso da terra. Foram identificadas áreas com até seis diferentes classes de restrições sobrepostas, tendo sido observado um alto estado de antropização na área de estudo, tendo aproximadamente $80 \%$ do território por algum uso agropecuário. Esse percentual foi observado também na categoria de APP de nascente, que são áreas importantes no que tange a questão de recursos hídricos. As áreas com diferentes restrições socioambientais sobrepostas e antropizadas devem ser priorizadas em ações de recuperação ambiental, visando, por exemplo a melhora na qualidade da água na UGRH do Paranapanema.

Palavras-chave: Áreas Restritivas; Sistemas de Informações Geográficas; Planejamento Ambiental; Gestão de Recursos Hídricos.

ABSTRACT: Territorial planning and management are processes based on the organization of geographic space, which has been consolidated by means of common assumptions and rules that make living in society feasible. Through various legal mechanisms it is possible to determine areas with some kind of socio-environmental restrictions on land use. The present study proposes to spatialize in an integrated way different types of restrictive areas within the Paranapanema Water Resources Management Unit, namely Permanent Preservation Areas, Conservation Units, Priority Areas for Conservation of the Brazilian Biodiversity, Indigenous Lands, Natural-Cultural Heritage, Water Sources and Settlements. From the integration of these layers of information, through the algebra of maps, it was possible to determine up to six different classes of restrictions in the same unit area. The percentage of anthropization (especially agricultural activities areas) of each restrictive area mapped from land use data was also evaluated. Areas with up to six different classes of overlapping restrictions were identified, having been observed a high anthropization level in the study area, with approximately $80 \%$ of the territory by some agricultural use. This percentage was also observed in the category of APP of springs, which are important areas in terms of water resources. The areas with different overlapping and anthropized socio-environmental restrictions should be prioritized in environmental recovery actions, aiming, for example, the improvement of water quality in the Paranapanema UGRH.

Keywords: Restrictive Areas; Geographic Information Systems; Environmental Planning; Water Resources Management.

Recebido: Maio 26, 2021. Revisado: Julho 05, 2021. Aceito: Agosto 26, 2021. 


\section{INTRODUÇÃO}

O planejamento e o ordenamento territorial são processos que começaram a ser desenvolvidos já no período da Idade Antiga (Antiguidade) por volta de 4.000 a.C., com a proposição da organização do espaço geográfico que foi se consolidando por meio de pressupostos e regras comuns que viabilizaram a vivência em sociedade. As primeiras formas de planejamento desenharam-se na Mesopotâmia, com atividades associadas à agricultura e à pesca, tornando-se mais notório na civilização grega com o planejamento das cidades (Santos, 2004). A abordagem ambiental no ordenamento do território, também denominada de planejamento ambiental surge em meados da década de 1970, do século XX, em virtude do grande antagonismo na busca por recursos ambientais, sendo necessária a estruturação do uso da terra de modo que se pudesse proteger ambientes ameaçados, visando preservar estratégias de sustentabilidade de forma que o espaço fosse organizado paulatinamente dentro de um contexto socioambiental (Santos, 2004; Massiris Cabeza, 2012; Gudiño, 2016). Para Silva \& Santos (2011) a análise do homem e da natureza de forma integrada, envolve diversas questões sociais, políticas e ecológicas na égide da visão sistêmica.

0 planejamento ambiental possui diversos instrumentos, dentre os quais o zoneamento ambiental. Essa ferramenta é uma das possíveis soluções para o ordenamento do uso racional dos recursos naturais, em face à amplificação da fronteira agrícola. 0 ordenamento se tornou imprescindível, uma vez que a urbanização, juntamente com a industrialização têm se intensificado de forma acelerada (Amorim \& Oliveira, 2013). No Brasil, a Lei $n^{\circ} 6.938 / 1981$ dispõe sobre a Política Nacional do Meio Ambiente (PNMA) e tem por objetivo "[...] a preservação, melhoria e recuperação da qualidade ambiental propícia à vida, visando assegurar, no País, condições ao desenvolvimento socioeconômico, aos interesses da segurança nacional e à proteção da dignidade da vida humana [...]" que tem como um dos seus instrumentos o zoneamento ambiental, bem como a criação de espaços territoriais especialmente protegidos (Brasil, 1981, Art $2^{\circ}$ ) partir da década de 1980 o planejamento ambiental foi absorvido por diversas instituições governamentais, contudo, foi amparado a partir de diferentes perspectivas devido às diferentes incumbências dos responsáveis pelo processo de planejamento (Santos, 2004). Silva \& Santos (2011, p. 35), frisam que se torna necessário "desenvolver conceitos e propostas metodológicas que efetivem medidas reais e quantitativas relacionadas ao meio ambiente, que simplifiquem a expressão dos resultados obtidos". Além disso, os mesmos autores salientam que com o zoneamento é possível delinear áreas para materializar no território a gestão ambiental.

Nesse sentido, no Brasil foi criado o Sistema Nacional de Unidades de Conservação (SNUC), regulamentado pela Lei $n^{\circ} 9.985 / 2000$, a fim de estipular padrões e normas para a formação, implementação e gestão das unidades de conservação, e possui como um de seus objetivos "promover o desenvolvimento sustentável a partir dos recursos naturais", além de "promover a utilização dos princípios e práticas de conservação da natureza no processo de desenvolvimento" (Brasil, 2000, Art. 4). Outra lei de importância é a Lei no 12.651/2012, que representa a evolução do código florestal brasileiro e tem como objetivo definir normas e critérios para a proteção da vegetação, Áreas de Preservação Permanente (APPs) e as áreas de reservas legais, além de atender o princípio da "[...] criação e mobilização de incentivos econômicos para fomentar a preservação e a recuperação da vegetação nativa e para promover o desenvolvimento de atividades produtivas sustentáveis" (Brasil, 2012, Art. 1). Para Nowatzki et al. (2016) esta lei preconiza a preservação de áreas estratégicas para o desenvolvimento sustentável do país, pois assegura porções do espaço geográfico que prestam serviços ecossistêmicos, sobretudo no tocante dos recursos hídricos, protegendo áreas como nascentes e matas ciliares.

No âmbito da questão hídrica, o conceito de gestão integrada de recursos hídricos, já preconizada no Plano Nacional de Recursos Hídricos (PNRH), estabelecido pela Lei no 9.433/97 é considerado a forma sustentável de gerir os recursos hídricos (Miranda, 2020). Visando sua implementação, governos internacionais modificam seu quadro legal e institucional para aumentar a participação local e implementar ferramentas de gestão de águas dentro do território da bacia hidrográfica. Miranda (2020) destaca que tais mudanças podem representar desafios para federações, pois a divisão de poderes entre os níveis nacional e subnacional é complexa, tendo em vista que uma mesma bacia pode abranger um ou mais estados federativos. Para Bitencourt et al. (2019), o enquadramento de corpos hídricos configurase como instrumento auxiliar da gestão de recursos hídricos desde a década de 1970, por meio da iniciativa de alguns estados, como São Paulo, Alagoas, Santa Catarina e Rio Grande do Norte. Em 1997, através da promulgação da Política Nacional de Recursos Hídricos se tornou oficialmente um instrumento de gestão. Contudo, no decorrer desses 20 anos, poucos Comitês de Bacia conseguiram elaborar propostas de enquadramento compatíveis com a legislação vigente e, menos ainda, estabeleceram adequados planos de efetivação e estratégias de implementação (Bitencourt et al., 2019). 
Levando em conta que o planejamento ambiental é importante para avaliação de um determinado território quanto aos seus aspectos socioeconômicos, políticos e ambientais, o presente trabalho tem como objetivos: (i) a realização do mapeamento de áreas com restrições socioambientais ao uso da terra (RSUT): (ii) avaliar seus graus de antropização presentes na Unidade de Gestão de Recursos Hídricos (UGRH) Paranapanema conforme as contribuições metodológicas de Silva \& Paula (2020). Esse método propõe a integração em uma só camada de informação, diferentes áreas restritivas, que são aquelas que apresentam porções do território com algum tipo de limitação legal ao uso da terra, na qual podem contribuir para tomadas de decisões em questões de gestão de recursos hídricos como as de enquadramento. Sendo assim, o mapeamento apresenta a quantidade máxima de restrições que uma unidade de área pode conter. Foram contempladas as seguintes áreas restritivas: cinco categorias de Áreas de Preservação Permanente (APP) e as Áreas de Uso Restrito (AUR), conforme a Lei de Proteção à Vegetação Nativa; Unidades de Conservação, divididos neste trabalho nas classes de Uso Sustentável (UUS), Proteção Integral (UPI), Reserva Particular do Patrimônio Natural (PPN) e Zonas de Amortecimento (ZAM). Ainda foram contempladas as Áreas Prioritárias para Conservação da Biodiversidade Brasileira (APR), Terras Indígenas (TIN), Tombamento Paisagístico Cultural (TOM), Mananciais de abastecimento público (MAN) e Assentamentos (ASS).

\section{MÉTODO}

\section{1 ÁREA DE ESTUDO}

A Resolução CNRH (Conselho Nacional de Recursos Hídricos) no 109, de 13 de abril de 2010 definiu as Unidade de Gestão de Recursos Hídricos (UGRH) de bacias hidrográficas de rios de domínio da União, visando orientar a priorização na implantação de Comitês de Bacia e a implementação dos instrumentos da Política Nacional de Recursos Hídricos (PNRH do ano de 1997). Conforme essa Resolução, a UGRH Paranapanema é constituída pela bacia hidrográfica do rio Paranapanema, nos Estados do Paraná e São Paulo. Posteriormente foi aprovada a Resolução CNRH n ${ }^{\circ} 120$ de 16 de dezembro de 2010 e o Decreto sem número de 5 de junho de 2012 que institui o Comitê da Bacia Hidrográfica do Rio Paranapanema. Conforme Parágrafo Único do último Decreto a área de atuação do CBH-PARANAPANEMA é definida pelos limites geográficos da bacia hidrográfica do rio Paranapanema. A bacia hidrográfica do rio Santo Anastácio, embora não faça parte da bacia hidrográfica do rio Paranapanema, é integrante da Unidades de Gestão Hídrica - UGH Pontal do Paranapanema, que é uma das três unidades de gestão da vertente paulista pertencentes ao CBH-PARANAPANEMA.

Para a definição das Unidades de Gestão Hídrica (UGHs) do Plano Integrado de Recursos Hídricos da Unidade de Gestão de Recursos Hídricos Paranapanema (Plano Integrado de Recursos Hídricos, 2006), foram consultadas as divisões hidrográficas adotadas pelas Unidades da Federação. Dessa forma, as UGHs são representadas, no âmbito do PIRH Paranapanema, pelas divisões hidrográficas estaduais, adotadas pelos Estados para a realização da gestão de recursos hídricos. Dessa forma, ficaram definidas seis UGHs: Alto Paranapanema, Médio Paranapanema e Pontal do Paranapanema, em São Paulo; Norte Pioneiro, Tibagi e Piraponema, no Paraná, conforme a Figura 1.

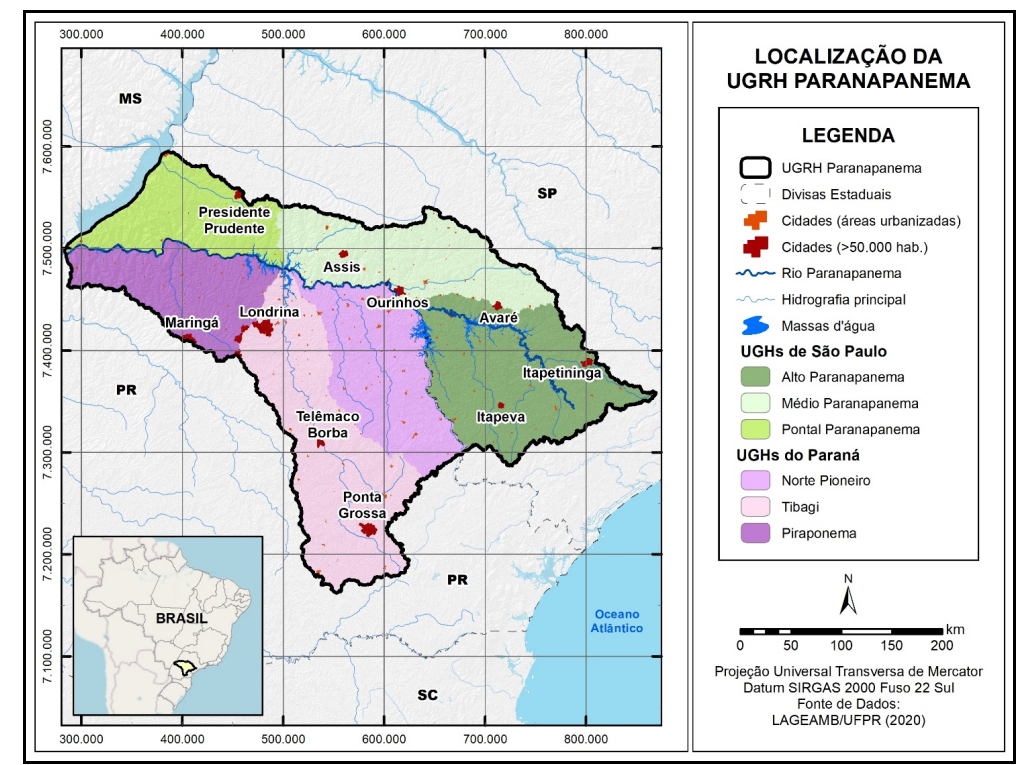

Figura 1. Localização da área de estudo (Unidade de Gestão de Recursos Hídricos do Paranapanema) e das Unidades de Gestão Hídrica (UGHs do PIRH Paranapanema) 


\subsection{MAPEAMENTO DAS ÁREAS RESTRITIVAS}

Para o mapeamento das áreas com restrições socioambientais, foi primeiramente organizada a base de dados de quinze áreas restritivas, para a qual seguiram-se os parâmetros presentes em Paz et al. (2020), detalhados em LAGEAMB (Laboratório de Geoprocessamento e Estudos Ambientais, 2020). Os dados geoespaciais foram padronizados em SIRGAS 2000 e aplicadas correções de topologia (como correção de gaps e overlaps), por meio do software ArcGIS 10.5. A síntese de todas as áreas restritivas consideradas neste estudo está representada na Tabela 1 com os seus respectivos dispositivos legais, fonte, data de aquisição do dado, valores de área em quilômetros quadrados e porcentagem em relação a área de estudo.

Tabela 1. Síntese das restrições socioambientais de uso da terra

\begin{tabular}{|c|c|c|c|c|c|c|}
\hline Área restritiva & Sigla & Dispositivo legal & Fonte & Data & $\begin{array}{l}\text { Área } \\
\left(\mathbf{k m}^{2}\right)\end{array}$ & $\begin{array}{l}\text { Área } \\
(\%)\end{array}$ \\
\hline APPs de Nascente & NAS & \multirow{6}{*}{$\begin{array}{l}\text { Lei } n^{\circ} 12.651 \text {, de } 25 \text { de } \\
\text { maio de } 2012 \text { (Brasil, } \\
\text { 2012) }\end{array}$} & LAGEAMB (UFPR) / ANA & 2020 & 54,7 & 0,05 \\
\hline $\begin{array}{c}\text { APPs de Hidrografia } \\
\text { unifilar }\end{array}$ & HIU & & $\begin{array}{l}\text { PIRH Paranapanema } \\
\text { /ANA }\end{array}$ & 2016 & $3.377,4$ & 3,17 \\
\hline $\begin{array}{l}\text { APPs de Hidrografia } \\
\text { bifilar }\end{array}$ & HIB & & $\begin{array}{c}\text { PIRH Paranapanema } \\
\text { /ANA }\end{array}$ & 2016 & 47,0 & 0,04 \\
\hline APPs de Reservatórios & RES & & GIA & 2013 & 466,9 & 0,44 \\
\hline APPs de Declividade & DEC & & LAGEAMB (UFPR) / NASA & 2019 & 6,3 & 0,01 \\
\hline Área de Uso Restrito & AUR & & LAGEAMB (UFPR) / NASA & 2019 & 552,4 & 0,52 \\
\hline UCs de Uso Sustentável & UUS & \multirow{4}{*}{$\begin{array}{l}\text { Lei n }{ }^{\circ} 9.985 \text {, de } 18 \text { de } \\
\text { julho de } 2000 \text { (Brasil, } \\
\text { 2000) }\end{array}$} & $\begin{array}{c}\text { GIA / IAT / MMA / } \\
\text { ICMBio } \\
\end{array}$ & 2020 & $6.733,6$ & 6,32 \\
\hline UCs de Proteção Integral & UPI & & $\begin{array}{c}\text { GIA / IAT / MMA / } \\
\text { ICMBio } \\
\end{array}$ & 2020 & $1.308,7$ & 1,23 \\
\hline $\begin{array}{c}\text { UCs de Reserva } \\
\text { Particular do Patrimônio } \\
\text { Natural } \\
\end{array}$ & PPN & & $\begin{array}{l}\text { GIA / IAT / MMA / } \\
\text { ICMBio }\end{array}$ & 2020 & 48,0 & 0,05 \\
\hline $\begin{array}{c}\text { Zonas de } \\
\text { Amortecimento de UCs } \\
\end{array}$ & ZAM & & GIA / IAT & 2020 & $3.219,8$ & 3,02 \\
\hline $\begin{array}{c}\text { Áreas prioritárias para } \\
\text { conservação da } \\
\text { biodiversidade }\end{array}$ & APR & \begin{tabular}{|c} 
Decreto $\mathrm{n}^{\circ} 5.092$ de $21 \mathrm{de}$ \\
maio de 2004 (Brasil, \\
2004 a) \\
\end{tabular} & $\begin{array}{l}\text { Ministério do Meio } \\
\text { Ambiente (MMA) }\end{array}$ & 2018 & $11.867,6$ & 11,14 \\
\hline Terras Indígenas & TIN & \begin{tabular}{|} 
Decreto $\mathrm{n}^{\circ} 5.051$, de 19 \\
de abril de 2004 (Brasil, \\
$2004 \mathrm{~b}$ ) \\
\end{tabular} & $\begin{array}{l}\text { Fundação Nacional do } \\
\text { Índio (FUNAI) }\end{array}$ & 2019 & 155,1 & 0,15 \\
\hline Tombamentos & TOM & $\begin{array}{l}\text { Lei Estadual 1.211/53 } \\
\text { (Paraná, 1953) }\end{array}$ & Instituto Purunã & 2020 & $1.815,1$ & 1,70 \\
\hline Mananciais & MAN & $\begin{array}{c}\text { PR: Lei Complementar } \mathrm{n}^{\circ} \\
\text { 170, de } 31 \text { de março de } \\
\text { 2014, que altera a Lei } \\
\text { Complementar no } 59 / 91 \\
\text { (Lei do ICMS Ecológico) } \\
\text { SP: Atlas do } \\
\text { Abastecimento Urbano } \\
\text { (Paraná, 2014b; Agência } \\
\text { Nacional de Águas, 2010) }\end{array}$ & $\begin{array}{l}\text { PR: Instituto das Águas } \\
\text { do Paraná } \\
\text { SP: Agência Nacional de } \\
\text { Águas (ANA) }\end{array}$ & 2020 & $30.019,1$ & 28,17 \\
\hline Assentamentos & ASS & $\begin{array}{c}\text { Norma de Execução DT no } \\
\text { 69/2008 (Brasil, 2008) }\end{array}$ & $\begin{array}{c}\text { Instituto Nacional de } \\
\text { Colonização e Reforma } \\
\text { Agrária (INCRA) } \\
\end{array}$ & 2020 & $2.049,7$ & 1,92 \\
\hline \multicolumn{2}{|l|}{ Total } & \multicolumn{5}{|c|}{$61.721,4$} \\
\hline
\end{tabular}

\subsection{1 ÁREAS DE PRESERVAÇÃO PERMANENTE (APPs)}

A delimitação das APPs foi realizada a partir da Lei de Proteção da Vegetação Nativa (Lei ${ }^{\circ}$ 12.651/2012), na qual tem-se o estabelecimento de parâmetros, definições e limites das APPs (Almeida et al., 2016; Nowatzki et al., 2010). As áreas de APPs, são protegidas, podendo ser cobertas ou não por vegetação nativa, tendo como função manter o ambiente equilibrado e assegurar o bem-estar das populações humanas (Brasil, 2012). As categorias de APPs selecionadas para compor as áreas restritivas foram, nascentes, mata ciliar de hidrografia unifilar (largura menor que 10 metros), mata ciliar de hidrografia bifilar (largura maior que 10 metros), reservatórios e declividades acima de $45^{\circ}$.

Conforme o Artigo 4음 da Lei Federal no 12.651/2012 (Brasil, 2012), considera-se APP em zonas rurais ou urbanas, para os efeitos desta Lei: as áreas no entorno das nascentes e dos olhos d'água perenes, qualquer que seja sua situação topográfica, no raio mínimo de 50 (cinquenta) metros. A 
delimitação das nascentes foi realizada a partir da rede de drenagem mapeada em escala 1:50.000 conforme os estudos de PIHR (Plano Integrado de Recursos Hídricos, 2006) tendo sua base disponibilizada pela Agência Nacional de Águas (ANA). Foram inseridos pontos em formato shapefile no início de cada segmento linear (hidrografia unifilar) e em seguida confeccionou-se buffers de 50 metros, nas 6.991 cabeceiras de canais de primeira ordem.

Para as APPs de rios que possuem até 10 metros de largura (hidrografia unifilar), de acordo com a Lei Federal "[...] devem possuir raio de proteção a partir de 30 metros para cada lado da margem, aumentando o raio de proteção conforme o aumento no tamanho da margem, chegando até o raio de 500 metros para cursos d'água com largura igual ou superior a 600 metros" (Silva \& Paula, 2020, p. 66). Para esta categoria de APP, foi necessário produzir um buffer de trinta metros em torno da hidrografia unifilar.

Já as APPs de rios que possuem mais de 10 metros de largura (hidrografia bifilar - escala 1:50.000), foram considerados, em zonas rurais ou urbanas, para os efeitos da Lei no 12.651/2012: 50 metros, para os cursos d'água que tenham de 10 a 50 metros de largura, 100 metros, para os cursos d'água que tenham de 50 a 200 metros de largura, 200 metros, para os cursos d'água que tenham de 200 a 600 metros de largura e 500 metros, para os cursos d'água que tenham largura superior a 600 metros. 0 mapeamento dessa categoria de APP foi realizado por meio da medição da largura de cada trecho do curso d'água, a partir da borda do seu leito regular. Após a medição foi realizada a confecção de buffers de acordo com as larguras, já mencionadas, dos trechos.

Para as APPs de Reservatórios, foi utilizada a Resolução no 302 de 20 de março de 2002 (Brasil, 2002), do Conselho Nacional do Meio Ambiente (CONAMA), conforme o Art. 3oㅡ, na qual constitui APP a área com largura mínima, em projeção horizontal, no entorno dos reservatórios artificiais, medida a partir do nível máximo normal de 30 metros para os reservatórios artificiais, situados em áreas urbanas consolidadas e cem metros para áreas rurais. Portanto, para a delimitação dessa categoria de APP foi preciso gerar um buffer de 100 metros em torno dos reservatórios, tendo em vista que todos se encontram em áreas rurais. Essa base de dados foi disponibilizada pelo Grupo Integrado de Aquicultura e Estudos Ambientais (Grupo Integrado de Aquicultura e Estudos Ambientais, 2013).

Para as APPs de Declividade foi utilizado o Artigo $4^{\circ}$ da Lei 12.651/2012 (Brasil, 2012), na qual considera as encostas ou partes destas com declividade superior a $45^{\circ}$ (equivalente a $100 \%$ ) na linha de maior declive. Para a extração da declividade foi utilizado o Modelo Digital de Elevação (MDE) disponibilizado pela National Aeronautics and Space Administration (NASA), através da missão o Shuttle Radar Topography Mission (SRTM), sendo que ele possui resolução de 30 (trinta) metros. Após, utilizou-se a ferramenta Slope do ArcToolBox do ArcGIS para gerar as declividades. Enquanto que as Áreas de Uso Restrito (AUR) são definidas de acordo com a Lei 12.651/2012, em seu Artigo 11, como áreas de inclinação entre $25^{\circ}$ e 45oㅡ nas quais são permitidos o manejo florestal sustentável e o exercício de atividades agrossilvopastoris, bem como a manutenção da infraestrutura física associada ao desenvolvimento das atividades, observadas boas práticas agronômicas, sendo vedada a conversão de novas áreas, excetuadas as hipóteses de utilidade pública e interesse social. Deste modo, para extração das classes desse intervalo de declividades, também foi utilizado a MDE SRTM, e a ferramenta Slope do ArcGIS.

De acordo com a Lei n 12.651/2012 (Brasil, 2012) é prevista ainda a delimitação da categoria de topo de morros, montes, montanhas e serras, que contemplem uma altura mínima de 100 metros e inclinação média maior que $25^{\circ}$. Essas áreas devem ser delimitadas através de curva de nível correspondente a $2 / 3$ da altura mínima da elevação em relação à base, definida pelo plano horizontal determinado por planície ou espelho d'água adjacente ou, nos relevos ondulados, pela cota do ponto de sela mais próximo da elevação. Por conta da significativa extensão e diversidade geomorfológica da área de estudo, somadas à complexidade do processo de delimitação dessa categoria de APP, verificouse como não sendo viável, no âmbito do presente estudo, delimitar essa categoria manualmente.

\subsubsection{UNIDADES DE CONSERVAÇÃO}

As Unidades de Conservação (UCs) são definidas, de acordo com a Lei no 9.985 de 18 de julho de 2000, como um espaço territorial em conjunto com seus recursos ambientais, abrangendo as águas jurisdicionais, com particularidades naturais relevantes, legalmente estabelecida pelo Poder Público, objetivando a conservação e limites pré-estabelecidos, sob regime especial de administração, ao qual se aplicam garantias de proteção (Brasil, 2000). As UCs integrantes do Sistema Nacional de Unidades de Conservação (SNUC), dividem-se em dois grupos: Unidades de Proteção Integral e Unidades de Uso Sustentável. A Unidade de Proteção Integral tem o objetivo 
de preservar a natureza, admitindo apenas o uso indireto dos recursos naturais, compostas pelas seguintes categorias: Estação Ecológica, Reserva Biológica, Parque Nacional, Monumento Natural, Refúgio da Vida Silvestre. Outrossim, as Unidades de Uso Sustentável objetivam compatibilizar a conservação da natureza com o uso sustentável de parcelas dos recursos naturais. As categorias que compõe essa unidade são as seguintes: Área de Proteção Ambiental, Área de Relevante Interesse Ecológico, Floresta Nacional, Reserva Extrativista, Reserva de Fauna, Reserva de Desenvolvimento Sustentável e Reserva Particular do Patrimônio Natural (Brasil, 2000).

No estado do Paraná, quando foi aprovado o Sistema Estadual de Unidades de Conservação (Paraná, 2007), a categoria Reserva Particular do Patrimônio Natural (RPPN) foi definida como Unidade de Proteção Integral, diferindo do disposto no SNUC. De acordo com a Secretaria de Infraestrutura e Meio Ambiente do estado de São Paulo, para o estado a classe de RPPN integra o grupo de Uso Sustentável. Desta forma, como área de estudo abrange os dois estados, se tornou necessária a separação das RPPNs em um dado distinto das demais categorias de Unidades de Conservação, tendo em vista essa diferente interpretação da classe em relação ao SNUC.

Ainda em conformidade a essa mesma legislação do SNUC (Brasil, 2000), foram consideradas para o estudo as Zona de Amortecimento (ou Zona Tampão) que é uma área estabelecida ao redor de uma unidade de conservação com o objetivo de mitigar os impactos negativos das atividades que ocorrem fora dela, como: ruídos, poluição, espécies invasoras e avanço da ocupação humana, especialmente nas unidades próximas a áreas intensamente ocupadas.

A área da UGRH Paranapanema contempla diferentes categorias de Unidades de Conservação, tendo sido utilizado neste trabalho shapefile publicado pelo Grupo Integrado de Aquicultura e Estudos Ambientais (Grupo Integrado de Aquicultura e Estudos Ambientais, 2013). Esta base foi revisada e atualizada a partir dos dados disponibilizados pelo Instituto Água e Terra (IAT) e pelo Ministério do Meio Ambiente (MMA). Salienta-se que os dados do MMA continham inconsistências e por isso optou-se por tomar por referência a base dos dados do GIA. É pertinente destacar que os dados desta base continham inúmeras UCs de nível municipal, vetorizadas ao longo do estudo do Instituto GIA através de interpretação de memoriais descritivos. Ainda, houve uma atualização dos dados de UCs por parte do IAT, contendo novas delimitações e a classe de zonas de amortecimento. Foi feita uma integração dessas três fontes de dados. Assim sendo, as 70 áreas restritivas relacionadas ao SNUC consideradas no trabalho são: Unidades de Conservação de Uso Sustentável, Unidades de Conservação de Proteção Integral, Reserva Particular do Patrimônio Natural e Zonas de Amortecimento. Na UGRH Paranapanema foram delimitadas igualmente no total 35 Unidades de Conservação de Uso Sustentável e 35 de Proteção Integral. Dentre elas pode-se citar a Áreas de Proteção Ambiental (APA) Estadual da Escarpa Devoniana (Campos Gerais), a APA Corumbataí - Botucatu - Tejupá, o Parque Estadual Morro do Diabo, o Parque Estadual Nascentes do Paranapanema e a Reserva Biológica das Araucárias. Para as RPPNs foram delimitadas 2 reservas no estado de São Paulo e 9 no Paraná e ainda 26 Zonas de Amortecimento no total.

\subsubsection{DEMAIS ÁREAS RESTRITIVAS}

No ano de 2018 foram disponibilizados pelo Ministério do Meio Ambiente (Brasil, 2018) os dados espaciais referentes à atualização das Áreas Prioritárias para Conservação da Biodiversidade Brasileira (APR). As informações para cada um dos biomas são sistematizadas em um único mapa e em fichas descritivas das áreas com suas ações recomendadas, além da informação de importância biológica e prioridade de ação. O processo de atualização foi elaborado regionalmente e utilizando sub-bacias hidrográficas como unidade mínima de informação do território. As áreas prioritárias para conservação da Mata Atlântica, onde se insere a UGRH do Paranapanema, ocorreu durante os anos de 2017 e 2018, por meio de várias reuniões técnicas temáticas, com a participação de pesquisadores, gestores de órgãos governamentais municipais, estaduais e federais, organização da sociedade civil, setores econômicos e representantes de diversas instituições (Brasil, 2018). Na UGRH Paranapanema foram delimitadas 24 áreas prioritárias.

Nos termos da legislação brasileira vigente (CF/1988, Lei 6001/1973 - Estatuto do Índio, Decreto n. $1775 / 1996)$, as Terras Indígenas (TIN) podem ser classificadas nas seguintes modalidades (Fundação Nacional do Índio, 2019): Terras Indígenas Tradicionalmente Ocupadas, Reservas Indígenas, Terras Dominiais, Interditadas. Sobre as Fases do Processo Administrativo em Terras Indígenas Tradicionalmente Ocupadas, de acordo com a Constituição 
Federal vigente, os povos indígenas detêm o direito originário e o usufruto exclusivo sobre as terras que tradicionalmente ocupam. As fases do procedimento demarcatório das terras tradicionalmente ocupadas, abaixo descritas, são definidas por Decreto da Presidência da República e atualmente consistem em: Em estudo, Delimitadas, Declaradas, Homologadas, Regularizadas e Interditadas. Conforme FUNAI (Fundação Nacional do Índio, 2019) a União poderá estabelecer, em qualquer parte do território nacional, áreas destinadas a posse e ocupação pelos povos indígenas, onde possam viver e obter meios de subsistência, com direito ao usufruto e utilização das riquezas naturais, garantindo-se as condições de sua reprodução física e cultural. Para a área de estudo foram encontradas 10 terras indígenas, sendo todas elas encontradas em território paranaense.

Em relação às áreas com a presença de paisagens tombadas como patrimônio natural (TOM) pode-se citar o andamento do processo referente ao tombamento da Escarpa Devoniana, presente na área de estudo. Os dados espaciais da escarpa devoniana foram disponibilizados pelo Instituto Purunã, em formato de polyline. 0 arquivo continha inconsistências, as quais foram corrigidas por topologia, bem como a conversão para o formato polygon. De acordo com SEEC (Paraná, 2021) a Coordenação do Patrimônio Cultural da Secretaria de Estado da Cultura do Paraná abriu processo de tombamento da Escarpa Devoniana do Paraná (no 08/2012), conforme publicado na edição no 9.285 do dia 05 de setembro de 2014 no Diário Oficial do Paraná, página 3. A abertura do processo teve a anuência do Conselho Estadual do Patrimônio Histórico e Artístico do Paraná - CEPHA, em sua 154ª Reunião Ordinária, realizada em 20 de agosto de 2014. Este complexo, que envolve as paisagens de campos naturais e ecossistemas associados à escarpa, importante patrimônio cultural paranaense, localiza-se na extrema porção ocidental do Segundo Planalto Paranaense, limítrofe ao Planalto de Curitiba. O perímetro apresentado para o processo de tombamento é de caráter preliminar e será objeto de estudos interdisciplinares para a definição dos limites definitivos para o tombamento da referida área de proteção ambiental. Ressalta-se que, uma vez aberto o processo de tombamento, o bem passa a ter a proteção da Lei Estadual 1211/1953, que dispõe sobre a preservação do Patrimônio Histórico, Artístico e Natural do Paraná, até a homologação do tombamento pelo referido Conselho. Após estudos iniciais, elaborou-se um Detalhamento do Perímetro Preliminar, considerando elementos físicos, geográficos, paisagísticos e do patrimônio cultural. Ressalta-se que seu caráter é ainda preliminar, porém já de uso administrativo a partir de 10 de maio de 2016. Observa-se que os estudos interdisciplinares para a proposição dos limites definitivos referentes ao processo de tombamento da "Escarpa Devoniana" continuam em andamento (Paraná, 2021).

A consistência dos dados de mananciais de abastecimento público (MAN) foi elaborada em duas etapas, pois como a área de estudo compreende duas unidades federativas diferentes (Paraná e São Paulo), foi preciso pesquisar diversas fontes, sendo que essas áreas são entendidas como fontes de água, superficiais ou subterrâneas, que podem ser usadas para o abastecimento público. Para o estado do Paraná, foi utilizada como base a Lei Complementar no 170 , de 31 de março de 2014, que altera a Lei Complementar no 59/1991, também conhecida como Lei do ICMS Ecológico (Paraná, 2014a), sendo o dado disponibilizado pelo IAT.

Em seu Artigo 3o é destacado que os municípios contemplados na presente Lei pelo critério de mananciais são aqueles que abrigam em seu território parte ou o todo de bacias hidrográficas de mananciais de abastecimento público atual para municípios vizinhos, e aqueles que abrigam em seu território parte ou o todo de áreas de interesse de mananciais de abastecimento público reconhecidas por decreto estadual. Foram delimitadas 26 áreas de mananciais dentro do território paranaense. Já para o estado de São Paulo, foram utilizados dados gerados a partir dos pontos de captação para abastecimento urbano de água da ANA, disponíveis no Atlas do Abastecimento Urbano (Agência Nacional de Águas, 2010). A partir desses pontos, foram geradas áreas de contribuição à montante dos mesmos com a ferramenta Hydrology do ArcGIS 10.5, tendo como base o Modelo Digital de Elevação SRTM banda C, versão 4 disponibilizado pelo Consortium for Spatial Information (CGIAR-CSI) dos Estados Unidos da América com resolução espacial é de aproximadamente 90 metros. Foram delimitadas nessa porção 32 áreas de mananciais.

Em relação aos assentamentos rurais (ASS) eles são entendidos conforme INCRA (Instituto Nacional de Colonização e Reforma Agrária, 2020) como um conjunto de unidades agrícolas independentes entre si, instaladas pelo INCRA onde originalmente existia um imóvel rural que 
pertencia a um único proprietário. Cada uma dessas unidades, chamadas de parcelas, lotes ou glebas, é entregue pelo INCRA a uma família sem condições econômicas para adquirir e manter um imóvel rural por outras vias. Os trabalhadores rurais que recebem o lote comprometem-se a morar na parcela e a explorá-la para seu sustento, utilizando exclusivamente a mão de obra familiar. Esses dados foram obtidos a partir da disponibilização no Sistema de Certificação de Imóveis Rurais, o qual o INCRA é responsável. Os dados são obtidos na escala municipal a partir dos Projetos de Assentamentos Federal e separadamente para os estados do Paraná e São Paulo. $\mathrm{Na}$ sequência foram agrupadas as 185 áreas com assentamentos em um único dado, em ambiente do software ArcGIS 10.5, no formato shapefile, recortados para a área de interesse e corrigidos topologicamente.

\subsection{PROCESSO DE DELIMITAÇÃO DAS ÁREAS COM RESTRIÇõES SOCIOAMBIENTAIS AO USO DA TERRA}

Após realizada a espacialização em formato shapefile das áreas restritivas consideradas neste trabalho, foi realizada a conversão dos dados vetoriais para o formato raster com a função polygon to raster no ArcGIS 10.5 e padronizados para a resolução espacial de 30 metros (Sampaio \& Brandalize, 2018), tendo em vista a adequação da geometria dos dados sobretudo pelo fato de que alguns dados foram elaborados a partir do SRTM de 30 metros, como as APPs de Declividade e as Áreas de Uso Restrito. A etapa seguinte foi a utilização da técnica da tabulação cruzada (TC) para a integração das variáveis a partir de superposição de mapas (álgebra de mapas). Esta técnica indica o conjunto de procedimentos de análise espacial em geoprocessamento, cujo resultado traz novos dados a partir de ferramentas aplicadas a um ou mais mapas. Esse método constitui-se da sobreposição de áreas restritivas na forma de matrizes (raster), para as quais são executadas operações algébricas em ambiente de SIG (Nowatzki, 2019). Neste trabalho foi atribuído valor de 1 para as quinze categorias de áreas restritivas ao uso da terra, e valor 0 para o restante da área de estudo. A equação utilizada para a álgebra de mapas foi a seguinte:

$R S U T=(N A S+H I U+H I B+R E S+D E C+A U R+U U S+U P I+P P N+Z A M+A P R+T I N+T O M+M A N+A S S)$

Deste modo, a partir da sobreposição de informações, foi possível espacializar em um único plano de informações as áreas que apresentam alguma informação de restrição por unidade de área (pixel de 30 metros), podendo ser encontradas áreas com nenhum tipo de restrição, assim como várias sobreposições.

\subsection{DETERMINAÇÃO DO ESTADO DE ANTROPIZAÇÃO}

Para o mapeamento do estado de antropização das áreas restritivas foi utilizado como base o mapeamento da Cobertura Vegetal e Uso da Terra, disponibilizado pelo Comitê de Bacia Hidrográfica do Paranapanema. Este mapeamento foi realizado por meio da aquisição de imagens do satélite LANDSAT 8 do ano de 2014, com a utilização das bandas de 2 a 7. A etapa seguinte constituiu-se em agrupar classes de uso da terra consideradas antropizadas e classes consideradas em seu estado natural de preservação, como áreas florestadas e campestres. A nomenclatura da cobertura terrestre (ou estado do uso da terra) foi concebida partindo do esquema teórico da cobertura terrestre, que abrange os dois primeiros níveis hierárquicos seguindo as propostas metodológicas do Manual Técnico de Uso da Terra (Instituto Brasileiro de Geografia e Estatística, 2013), conforme a Figura 2. 


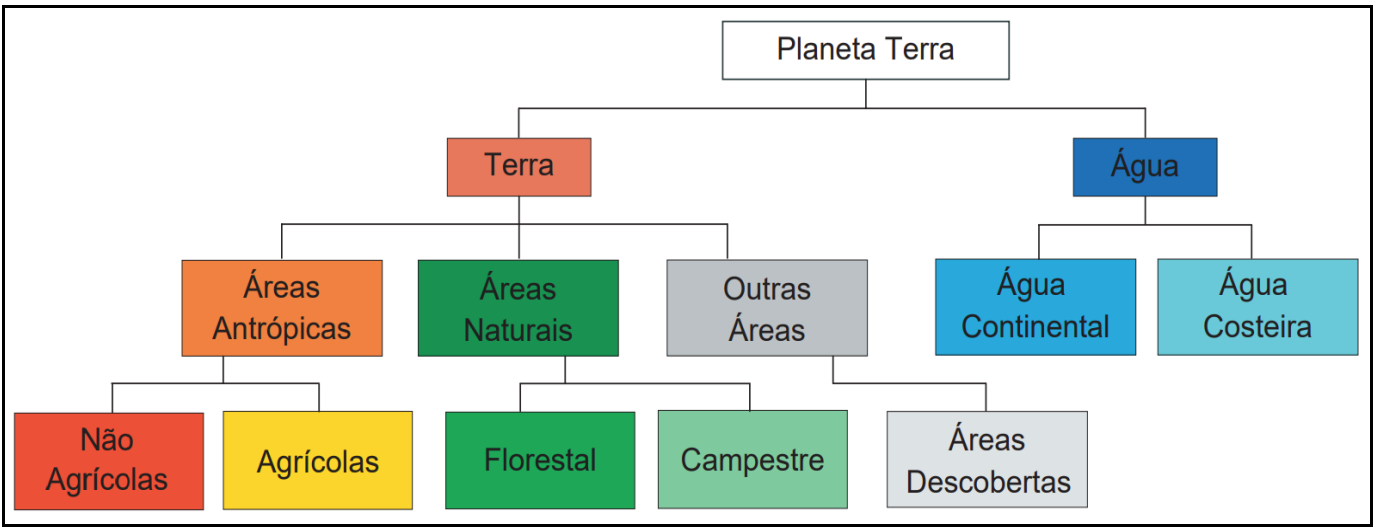

Figura 2. Esquema teórico de construção de uma nomenclatura da cobertura terrestre Fonte: IBGE (Instituto Brasileiro de Geografia e Estatística, 2013)

A partir destes dados agruparam-se em ambiente SIG (Sistemas de Informações Geográficas) as classes consideradas como áreas em estado natural e em estado antrópico foram agregadas conforme a Tabela 2. Salienta-se que as classes de reservatórios, lagos, açudes e corpos d'água foram consideradas neste trabalho como a classe Água.

Tabela 2. Nomenclatura da cobertura terrestre e classes de uso da terra

\begin{tabular}{c|c}
\hline Classe & Nomenclatura da cobertura terrestre \\
\hline Campestre & \multirow{2}{*}{ Áreas naturais } \\
\hline Florestal & \\
\hline Área Urbanizada & \\
\hline Cultura Permanente - Café & \multirow{2}{*}{ Áreas antrópicas } \\
\hline Cultura Permanente - Citrus & \\
\hline Cultura Temporária - Cana & \\
\hline Cultura Temporária - Milho/Soja & \\
\hline Pastagem & \\
\hline Silvicultura & \\
\hline
\end{tabular}

Após a realização desse agrupamento, por meio da ferramenta Intersect do ArcGIS, uma intersecção dessas informações agregadas com as áreas restritivas, como todas as categorias de APPs ou grupos de Unidades de Conservação, assim como também foi realizada a mesma estimativa para as restrições socioambientais, a fim de espacializar e quantificar quais as porções dentro dessas áreas encontram-se em estado de uso da terra considerado antropizado.

\section{RESULTADOS}

\subsection{MAPEAMENTO DAS ÁREAS COM RESTRIÇõES SOCIOAMBIENTAIS}

Após a organização dos dados das áreas restritivas, sendo eles as APPs, UCs, Áreas Prioritárias para Conservação da Biodiversidade Brasileira, Terras Indígenas, Tombamentos, Mananciais e Assentamentos foi possível realizar uma análise espacial integrada, levando em consideração as restrições socioambientais ao uso da terra, tomando por base o método usado por Silva \& Paula (2020). A Figura 3 destaca a espacialização das quinze áreas restritivas consideradas neste estudo para a UGRH Paranapanema. 


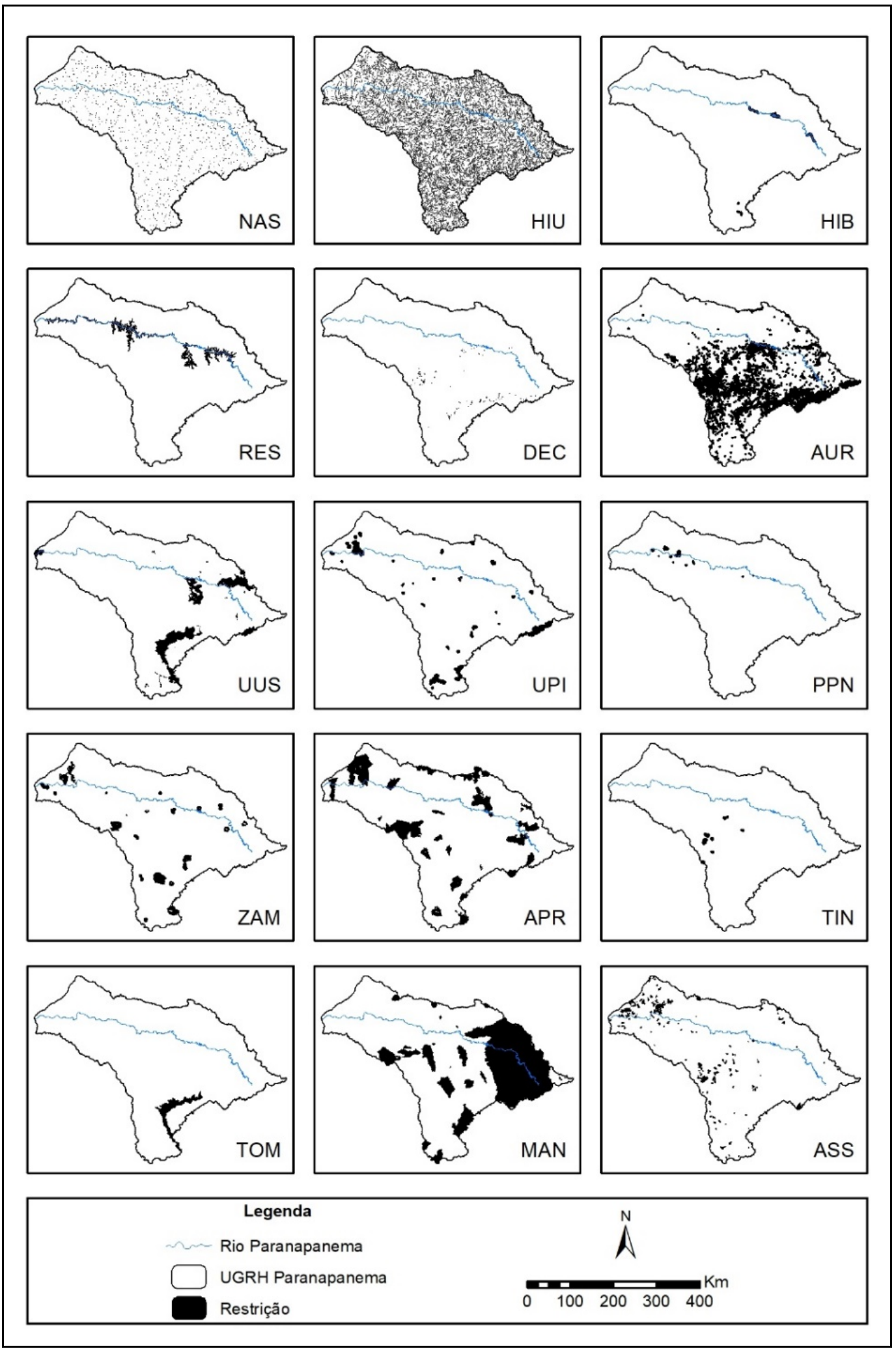

Figura 3. Áreas restritivas da UGRH Paranapanema

Legenda: APPs de Nascente (NAS), APPs de Hidrografia unifilar (HIU), APPs de Hidrografia bifilar (HIB), APPs de Reservatórios (RES), APPs de Declividade (DEC), Áreas de Uso Restrito (AUR), UCs de Uso Sustentável (UUS), UCs de Proteção Integral (UPI), Reserva Particular do Patrimônio Natural (PPN), Zonas de Amortecimento (ZAM), Áreas Prioritárias para Conservação da Biodiversidade Brasileira (APR), Terras Indígenas (TIN), Tombamento Paisagístico Cultural (TOM), Mananciais de abastecimento público (MAN) e Assentamentos (ASS). 
0 resultado da álgebra de mapas poderia variar de zero (áreas sem qualquer restrição ao uso da terra) até áreas com no máximo quinze restrições, já que foram elencadas quinze informações geoespaciais diferentes. No entanto, a somatória máxima para a área de estudo foi a de combinação de 6 restrições socioambientais ao uso da terra, conforme a Figura 4. A Tabela 3 representa o cálculo de área para essas classes.

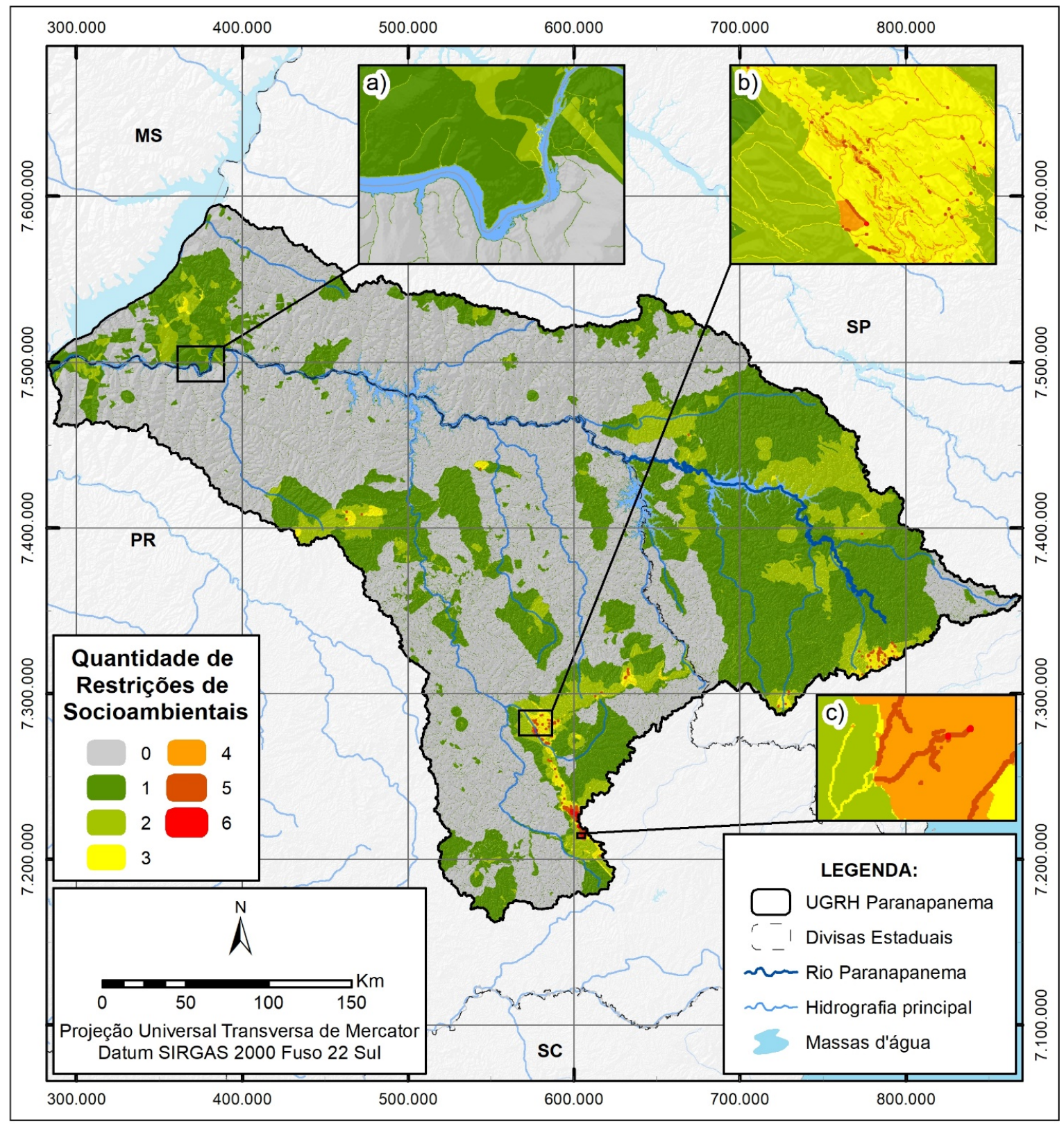

Figura 4. Restrições socioambientais ao uso da terra da UGRH Paranapanema Legenda: a) Proximidades do Parque Estadual Morro do Diabo, as margens do rio Paranapanema; b) Proximidades do Parque Estadual Guartelá, situado dentro da APA da Escarpa Devoniana; c) Proximidades do Parque Estadual Campos Gerais, situado dentro da área do Tombamento da Escarpa Devoniana. 
Tabela 3. Quantificação de área para as classes de restrições socioambientais ao uso da terra na UGRH Paranapanema

\begin{tabular}{c|c|c}
\hline Quantidade de restrições & Área (Km $\left.{ }^{2}\right)$ & Área (\%) \\
\hline 0 & $58.232,18$ & 54,65 \\
\hline 1 & $36.520,13$ & 34,27 \\
\hline 2 & $10.165,64$ & 9,54 \\
\hline 3 & $1.476,46$ & 1,39 \\
\hline 4 & 155,23 & 0,15 \\
\hline 5 & 4,85 & 0,005 \\
\hline 6 & 0,05 & 0,00004 \\
\hline Total & $\mathbf{1 0 6 . 5 5 4 , 5 3}$ & $\mathbf{1 0 0}$ \\
\hline
\end{tabular}

$\mathrm{Na}$ área de estudo foram observadas até seis níveis de restrições sobrepostas. Na Figura 4a observam-se áreas com até 2 níveis de restrições, estando estas situadas nas margens do Paranapanema, onde localiza-se a Unidade de Conservação do Parque Estadual Morro do Diabo, município de Teodoro Sampaio. A Figura 4b destaca as proximidades do Parque Estadual Guartelá, no município de Tibagi, evidenciando todos os níveis mapeados de restrições socioambientais, sendo que o parque se encontra dentro da área da APA da Escarpa Devoniana, assim como na área de tombamento da referida escarpa. Outros tipos de áreas restritivas são encontrados nessa porção, como APPs de nascentes e hidrografia unifilar, zonas de amortecimento de UCs, áreas de uso restrito e áreas prioritárias a conservação da biodiversidade brasileira. A Figura 4c evidencia o Parque Estadual Campos Gerais, localizado no município de Tibagi, e seu entorno. Este parque está inserido na APA e na área de tombamento da Escarpa Devoniana, o que explica a ocorrência das classes de 6, 5 e 4 restrições socioambientais. Nota-se ainda a proeminência das APPs de cursos hídricos, como nascentes e matas ciliares de hidrografia unifilar.

Destaca-se que a classe com zero restrições, a qual ocupa a maior área dentre as classes mapeadas, com aproximadamente 55\% da área, são porções da UGRH em que pode haver outros tipos de restrições que não foram contempladas neste estudo. Como exemplo, para o estado do Paraná pode-se citar a Resolução Conjunta IBAMA/SEMA/IAP nº 005 que conceitua as áreas úmidas como "[...] segmento de paisagem constituído por solos hidromórficos [...]" (Paraná, 2008, Art. 2), ou seja, o solo naturalmente caracterizado pela presença de água subsuperficial, geralmente, dentro de $50 \mathrm{~cm}$ a partir da superfície. Essa resolução se baseou na concepção do regime hídrico dos solos para avaliar as áreas úmidas e seus entornos protetivos, os quais correspondem às áreas restritivas ao uso da terra.

Outra questão a ser abordada é que nessas áreas onde não foi apresentado nenhum tipo de restrição, podem corresponder a porções de Reservas Legais, destacadas na Lei de Proteção à Vegetação Nativa (Brasil, 2012). Importante salientar que se cogitou adicionar essas áreas como uma camada de restrição socioambiental, mas pelo fato de que se acessa esse dado através da plataforma SICAR (Sistema Nacional de Cadastro Ambiental Rural), onde são dados de caráter declaratório e com potencial de conter diversos erros de caráter cartográfico, optou-se por não incluir essa classe no estudo. Outras classes podem ser adicionadas em estudos de restrições socioambientais, como áreas de recarga de aquífero, manguezais, restingas, vegetação primária e secundária em estágio médio e avançado, terrenos de marinha delimitados, áreas com riscos geotécnicos (inundações, deslizamentos), territórios tradicionais (quilombolas, populações ribeirinhas como caiçaras), entre outros.

\subsection{ESTADO DE ANTROPIZAÇÃO DAS ÁREAS RESTRITIVAS}

Na Tabela 4 é possível analisar as classes consideradas neste mapeamento, bem como as suas respectivas áreas. A Figura 5 ilustra a espacialização dessas classes. A UGRH do Paranapanema se encontra em um estado de antropização de aproximadamente $80 \%$, reflexo de seu uso da terra majoritário que é de pastagem e culturas temporárias (milho e soja). 
Tabela 4. Classes de cobertura vegetal e uso da terra na UGRH Paranapanema para o ano de 2014

\begin{tabular}{|c|c|c|c|}
\hline Classe de Cobertura Vegetal e Uso da Terra & $\begin{array}{l}\text { Nomenclatura da } \\
\text { cobertura terrestre }\end{array}$ & Área $\left(\mathrm{Km}^{2}\right)$ & Área (\%) \\
\hline Florestal & \multirow{3}{*}{ Áreas Naturais } & $14.758,66$ & 13,85 \\
\hline Campestre & & $4.354,57$ & 4,09 \\
\hline Subtotal & & $19.113,23$ & 17,9 \\
\hline Pastagem & \multirow{10}{*}{ Áreas Antrópicas } & $38.620,00$ & 36,24 \\
\hline Cultura Temporária - Milho/Soja & & $15.716,98$ & 14,75 \\
\hline Cultura Temporária - Cana & & $10.798,98$ & 10,13 \\
\hline Silvicultura & & $8.806,21$ & 8,26 \\
\hline Cultura Temporária & & $8.257,43$ & 7,76 \\
\hline Área Urbanizada & & $1.168,56$ & 1,10 \\
\hline Cultura Temporária - Pivôs & & 881,81 & 0,83 \\
\hline Cultura Permanente - Café & & 733,90 & 0,69 \\
\hline Cultura Permanente - Citrus & & 318,14 & 0,30 \\
\hline $\begin{array}{l}\text { Subtotal } \\
\end{array}$ & & $85.302,01$ & 80,1 \\
\hline Reservatórios, lagos, açudes e corpos d'água & Corpos Hídricos & $2.139,29$ & 2,00 \\
\hline \multicolumn{2}{|l|}{ Total } & $106.554,53$ & 100 \\
\hline
\end{tabular}

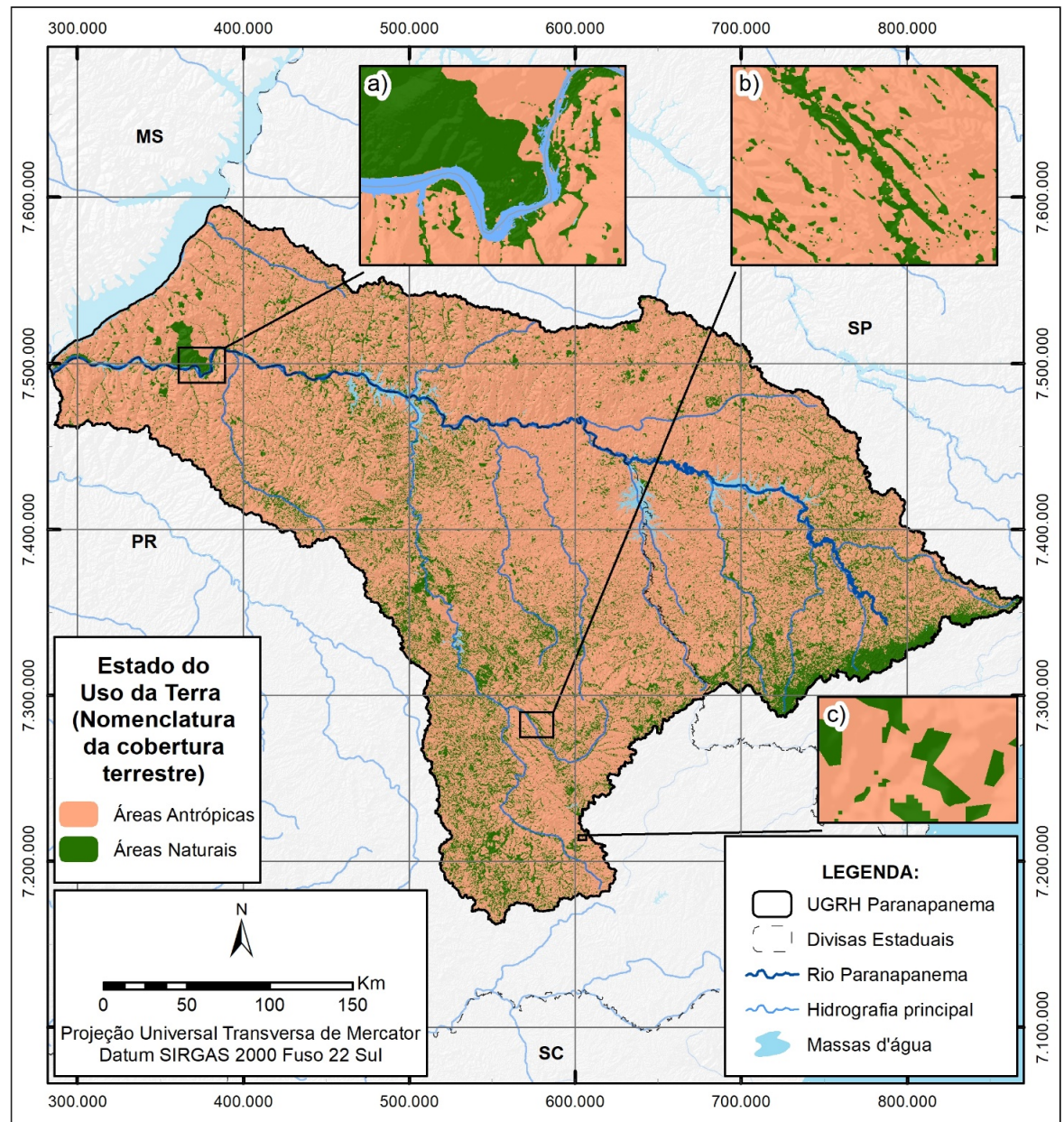

Figura 5. Estado do uso da terra: Antrópico e Natural

Legenda: a) Proximidades do Parque Estadual Morro do Diabo, as margens do rio Paranapanema; b) Proximidades do Parque Estadual Guartelá; c) Proximidades do Parque Estadual Campos Gerais.

A etapa seguinte constituiu-se em quantificar o grau de antropização para das classes de APPs contempladas (Tabela 5). 
Tabela 5 - Estado de antropização das classes de APP e classe de Uso Restrito

\begin{tabular}{cc|c|c|c|c}
\hline \multirow{2}{*}{ Classe de APP } & $\begin{array}{c}\text { Total } \\
\left(\mathbf{K m}^{2}\right)\end{array}$ & $\begin{array}{c}\text { Antrópico } \\
\left(\mathbf{K m}^{2}\right)\end{array}$ & \multicolumn{2}{c}{ Natural (Km ${ }^{2}$ ) } & \multicolumn{2}{c}{ Antrópico (\%) } & Natural (\%) \\
\hline Nascente & 54,7 & 45,9 & 8,9 & 83,8 & 16,2 \\
\hline Hidrografia unifilar & $3.377,4$ & $1.793,1$ & $1.584,3$ & 53,1 & 46,9 \\
\hline Hidrografia bifilar & 47,0 & 30,1 & 16,9 & 64,1 & 35,9 \\
\hline Reservatórios & 466,9 & 331,4 & 135,6 & 71,0 & 29,0 \\
\hline Declividade & 6,3 & 3,8 & 2,5 & 60,7 & 39,3 \\
\hline Área de Uso Restrito & 552,4 & 249,4 & 303,1 & 45,1 & 54,9 \\
\hline Total & $\mathbf{4 . 5 0 4 , 7}$ & $\mathbf{2 . 4 5 3 , 6}$ & $\mathbf{2 . 0 5 1 , 3}$ & $\mathbf{5 4 , 5}$ & $\mathbf{4 5 , 5}$ \\
\hline
\end{tabular}

Observa-se que o valor de antropização em áreas de nascente foi de 83,8\%. Desde modo, foi feita a identificação de quais as classes de uso da terra predominantes nesta categoria, conforme a Figura 6. Nota-se a predominância de usos antrópicos, sobretudo a classe de Pastagem que obteve 40,8\% da predominância sobre as áreas de nascentes.

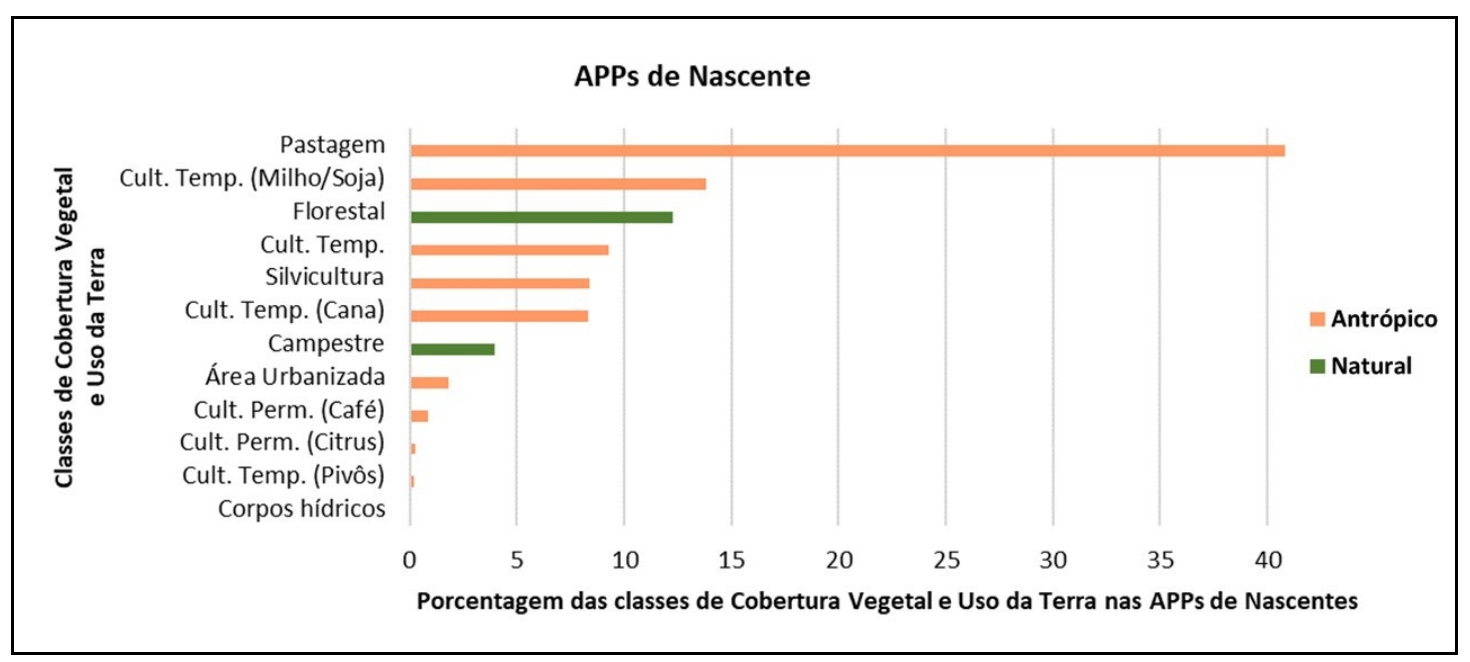

Figura 6. Porcentagem das diferentes classes de Cobertura Vegetal e Uso da Terra das APPs de Nascente

Esse mesmo diagnóstico foi feito para as demais áreas restritivas considerados neste estudo. A Tabela 7 compreende o grau de antropização das UCs de Uso Sustentável, Proteção Integral, Reservas Particulares do Patrimônio Natural e as Zonas de Amortecimento de UCs.

Tabela 7. Antropização de UC de Uso Sustentável, Proteção Integral, Reserva Particular do Patrimônio Natural e de Zonas de Amortecimento

\begin{tabular}{|c|c|c|c|c|c|c|c|c|}
\hline UC & Classe & $\begin{array}{r}\text { Total } \\
\left(\mathrm{Km}^{2}\right) \\
\end{array}$ & $\begin{array}{c}\text { Antrópico } \\
\left(\mathrm{Km}^{2}\right)\end{array}$ & $\begin{array}{c}\text { Natural } \\
\left(\mathrm{Km}^{2}\right)\end{array}$ & $\begin{array}{l}\text { Água } \\
\left(\mathrm{Km}^{2}\right)\end{array}$ & $\begin{array}{c}\text { Antrópico } \\
(\%)\end{array}$ & $\begin{array}{c}\text { Natural } \\
(\%)\end{array}$ & $\begin{array}{l}\text { Água } \\
(\%)\end{array}$ \\
\hline \multirow{4}{*}{$\begin{array}{l}\text { Uso Sustentável } \\
\text { (UUS) }\end{array}$} & APA & $6.576,9$ & $5.205,2$ & $1.334,5$ & 37,2 & \begin{tabular}{|l|}
79,1 \\
\end{tabular} & 20,3 & 0,6 \\
\hline & Floresta & 152,7 & 108,0 & \begin{tabular}{|l|}
44,7 \\
\end{tabular} & - & 70,7 & 29,3 & 0,0 \\
\hline & Horto & 3,0 & 1,1 & 1,9 & - & 37,6 & 62,4 & 0,0 \\
\hline & Reserva Florestal & 0,12 & 0,03 & \begin{tabular}{|l|}
0,09 \\
\end{tabular} & - & 25,6 & 74,4 & 0,0 \\
\hline \multicolumn{2}{|r|}{ Total } & $6.732,7$ & $6.732,7$ & $1.381,1$ & 37,2 & 78,9 & 20,5 & 0,6 \\
\hline \multirow{5}{*}{$\begin{array}{c}\text { Proteção } \\
\text { Integral (UPI) }\end{array}$} & Estação Ecológica & 214,2 & 36,2 & 177,9 & 0,1 & 16,9 & 83,0 & 0,1 \\
\hline & Monumento Natural & 2,2 & 1,1 & 1,1 & - & 49,0 & 51,0 & 0,0 \\
\hline & Parque & 942,4 & 118,6 & 823,0 & 0,8 & 12,6 & 87,3 & 0,1 \\
\hline & $\begin{array}{l}\text { Refúgio da Vida } \\
\text { Silvestre }\end{array}$ & 0,8 & 0,1 & 0,7 & - & 14,3 & 85,7 & 0,0 \\
\hline & Reserva Biológica & 149,2 & 22,1 & 127,1 & - & 14,8 & 85,2 & 0,0 \\
\hline \multicolumn{2}{|c|}{$\begin{array}{c}\text { Total } \\
\end{array}$} & $1.308,7$ & $1.308,7$ & $1.129,8$ & 1,0 & 13,6 & 86,3 & 0,1 \\
\hline \multicolumn{2}{|c|}{$\begin{array}{l}\text { Reserva Particular do Patrimônio } \\
\text { Natural }\end{array}$} & 48,0 & 8,8 & 39,2 & - & 81,6 & 18,4 & $\mathbf{0 , 0}$ \\
\hline \multicolumn{2}{|c|}{ Zonas de Amortecimento } & $3.219,8$ & $2.722,0$ & 492,5 & 5,3 & 84,5 & 15,3 & 0,2 \\
\hline
\end{tabular}


Destaca-se que o grupo de UCs de Proteção integral se encontram em um grau de preservação muito maior que as de Uso Sustentável (Figura 7). Nota-se ainda um alto grau de antropização das Zonas de Amortecimento (84,5\%). Para as UCs de Uso Sustentável, as áreas antropizadas são 78,9\%, destacando a categoria de Área de Proteção Ambiental (APA) que apresentou o maior grau de degradação com 79,1\%. Em contrapartida, para os dados de UPI as áreas com uso antrópico são de 13,6\%.

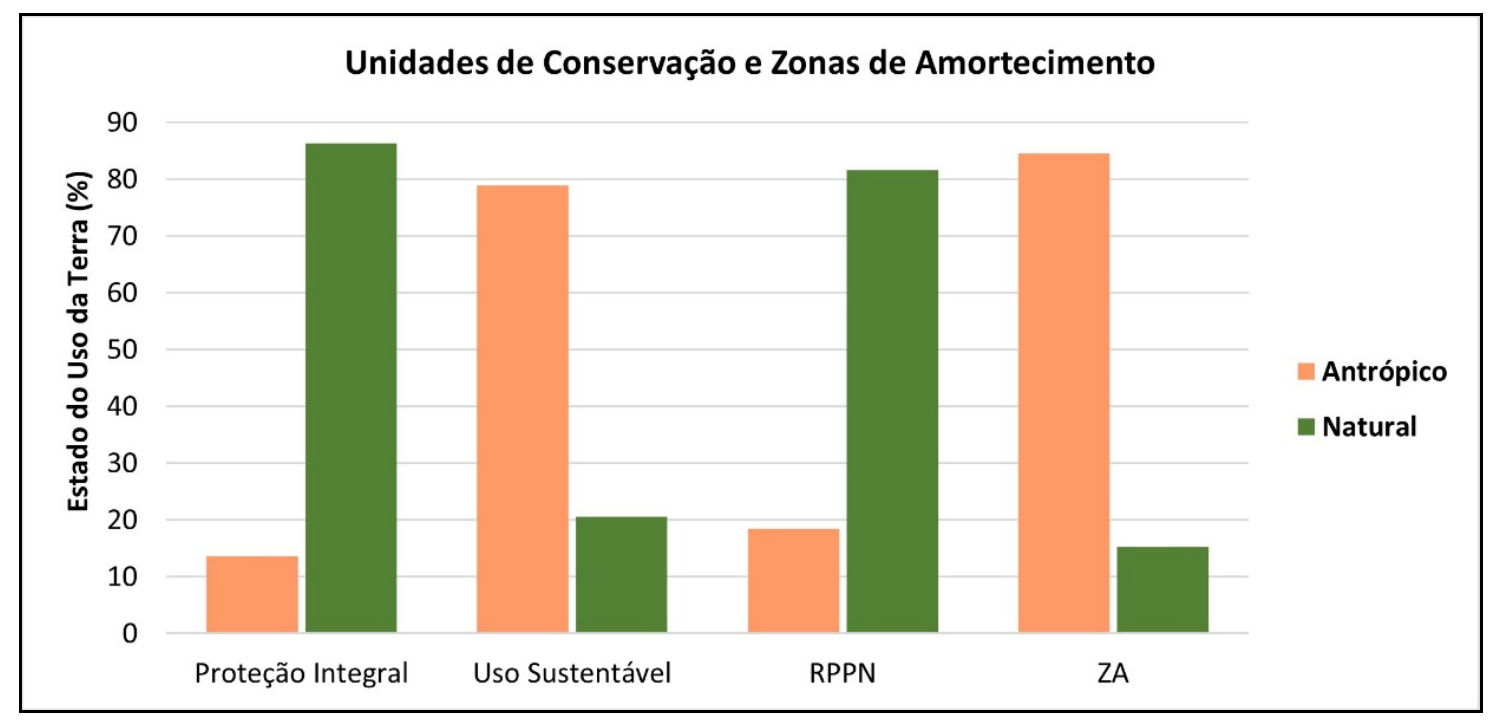

Figura 7. Estado de uso da terra das UCs e Zonas de Amortecimento

Importante destacar que a maior Área de Proteção Ambiental na área de estudo é a da Escarpa Devoniana, que vem sofrendo constantes tentativas para sua diminuição. É pertinente salientar que a APA da Escarpa Devoniana, localizada na porção leste do estado do Paraná foi criada através do Decreto Estadual no 1.231, de 27 de março de 1992, com o objetivo de assegurar a proteção do limite natural entre o Primeiro e o Segundo Planaltos Paranaenses, inclusive faixa de Campos Gerais, que se constituem em ecossistema peculiar que alterna capões da floresta de araucária, matas de galerias e afloramentos rochosos, além de locais de beleza cênica como os cânions e de vestígios arqueológicos e pré-históricos (Instituto Ambiental do Paraná, 2004). Por fim, foram realizados os cálculos de degradação e preservação, a partir do estado de uso da terra para os dados de Áreas Prioritárias para Conservação da Biodiversidade Brasileira, Terras Indígenas, Tombamentos, Mananciais e Assentamentos (Tabela 8).

Tabela 8. Antropização de áreas restritivas

\begin{tabular}{|c|c|c|c|c|c|c|c|c|}
\hline Área restritiva & Classe & Total $\left(\mathrm{Km}^{2}\right)$ & $\begin{array}{c}\text { Antrópico } \\
\left(\mathrm{Km}^{2}\right)\end{array}$ & $\begin{array}{c}\text { Natural } \\
\left(\mathrm{Km}^{2}\right)\end{array}$ & $\begin{array}{l}\text { Água } \\
\left(\mathrm{Km}^{2}\right)\end{array}$ & $\begin{array}{c}\text { Antrópico } \\
(\%)\end{array}$ & $\begin{array}{c}\text { Natural } \\
(\%)\end{array}$ & $\begin{array}{l}\text { Água } \\
(\%)\end{array}$ \\
\hline \multirow{3}{*}{$\begin{array}{c}\text { Áreas } \\
\text { Prioritárias para } \\
\text { Conservação da } \\
\text { Biodiversidade } \\
\text { Brasileira } \\
\end{array}$} & Alta & $4.185,7$ & $3.376,8$ & 731,5 & 77,4 & 80,7 & 17,5 & 1,8 \\
\hline & Muito alta & $7.546,2$ & $6.106,5$ & $1.368,8$ & 70,8 & 80,9 & 18,1 & 0,9 \\
\hline & $\begin{array}{c}\text { Extremamente } \\
\text { alta }\end{array}$ & 135,7 & 102,3 & 33,4 & - & 75,4 & 24,6 & 0,0 \\
\hline \multicolumn{2}{|c|}{ Total } & $11.867,6$ & $2.133,8$ & $9.585,6$ & 148,2 & 80,8 & 18,0 & 1,2 \\
\hline \multicolumn{2}{|c|}{ Terras Indígenas } & 155,1 & 67,2 & 87,5 & 0,3 & 43,4 & 56,4 & 0,2 \\
\hline \multicolumn{2}{|c|}{ Tombamentos } & $1.815,1$ & $1.473,4$ & 338,1 & 3,6 & 81,2 & 18,6 & 0,2 \\
\hline \multicolumn{2}{|c|}{ Mananciais } & $30.019,1$ & $22.727,6$ & $6.788,6$ & 502,9 & 75,7 & 22,6 & 1,7 \\
\hline \multicolumn{2}{|c|}{ Assentamentos } & $2.049,7$ & $1.601,4$ & 446,8 & 1,5 & 78,1 & 21,8 & 0,1 \\
\hline
\end{tabular}


Nota-se que apenas as Terras Indígenas apresentam maiores áreas naturais em relação as antropizadas. Para as Áreas Prioritárias para a Conservação da Biodiversidade, em todas as suas classes a degradação (antrópico) é superior à de preservação (natural), que chega no valor máximo de 24,6\% para a classe Extremamente Alta. Por fim, foi realizado o cálculo de áreas degradadas e preservadas das seis classes restrições de uso da terra, na qual as suas proporções podem ser analisadas na Figura 8.

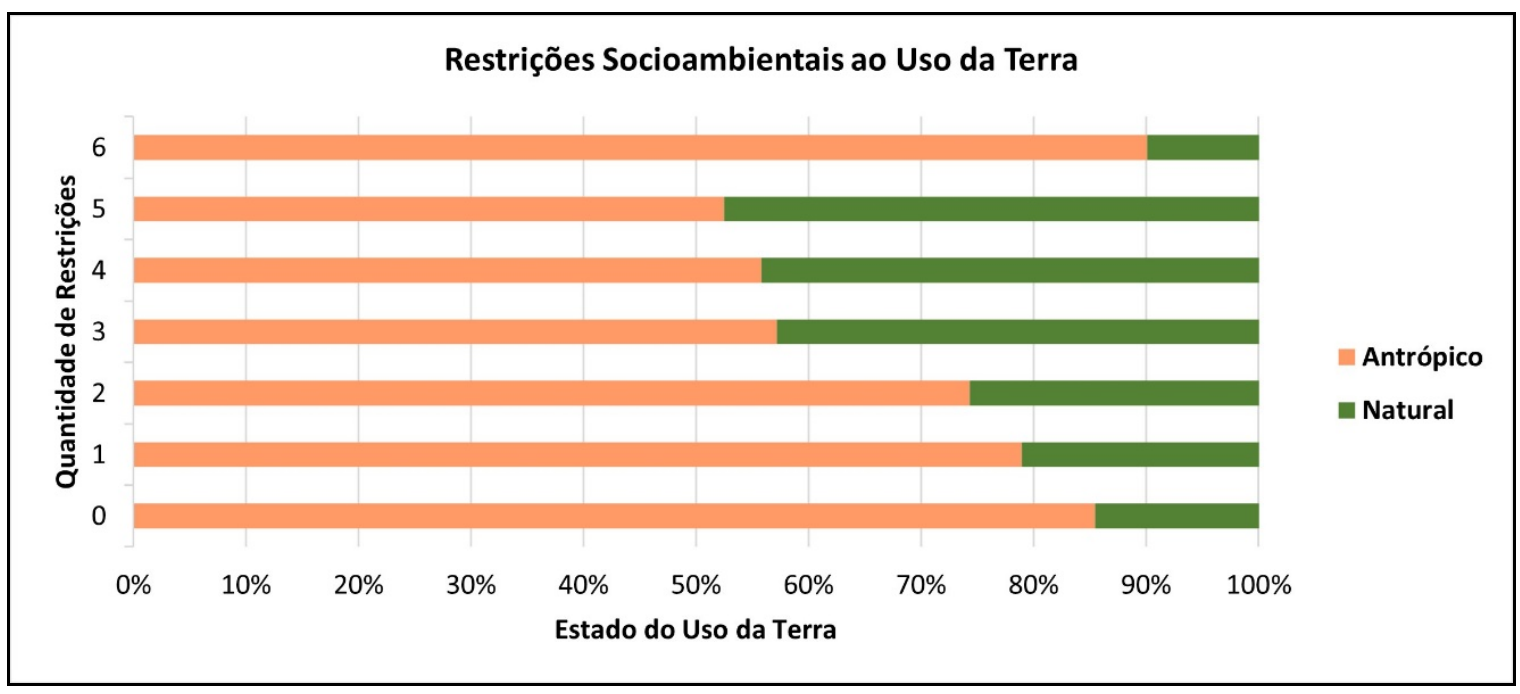

Figura 8. Percentual de áreas antropizadas e naturais nas classes de restrições socioambientais

Observa-se a diminuição das áreas com algum tipo de restrição, sendo que a classe com cinco áreas restritivas se encontra aproximadamente 50\% antropizada. Contudo, as áreas com seis restrições se apresentam com quase $90 \%$ o que demonstra que essas áreas possuem inúmeras restrições legais ao uso da terra e não estão sendo respeitadas, mesmo sendo APP, UC ou qualquer outra classe. Por exemplo, foi identificada uma área dentro do município de Ponta Grossa no estado do Paraná (Figura 4c) onde há pastagem em uma mesma unidade de área com seis restrições socioambientais. Foi identificado naquela porção do território as seguintes áreas restritivas: UC Parque Estadual Campos Gerais, a qual está dentro da APA e da área de Tombamento da Escarpa Devoniana; zona de amortecimento do Parque Estadual Vila Velha e as APPs de Nascente e de mata ciliar para Hidrografia unifilar. Por serem áreas de pastagem (ou qualquer outro tipo de classe de uso agrícola) Nowatzki et al. (2010) advertem que quando as mesmas ocorrem dentro de áreas de APPs, devido à suscetibilidade das mesmas, conforme enfatizado na Lei de Proteção da Vegetação Nativa, pode acarretar o desenvolvimento de processos erosivos, os quais podem intensificar o assoreamento de rios. Essa informação pode ser fundamental para servir de indicador para áreas críticas que demandam algum tipo de intervenção, seja por parte do poder público ou até mesmo servir como áreas estratégias para servirem como áreas piloto para se aplicar educação ambiental.

\subsection{POTENCIALIDADES PARA A GESTÃO DE RECURSOS HÍDRICOS}

A base conceitual para adequar inovações aos desafios da gestão do território e de recursos hídricos, permitir avaliar as variações de escala temporal no espaço geográfico, considerando não somente a dinâmica de uso da terra e seus registros de impactos quali-quantitativos, como também de entender as restrições socioambientais marcantes e necessárias definidas pela Legislação Ambiental, vigente no território brasileiro. Este conceito, embora não consolidado em resoluções e normas, representa a oportunidade de viabilização em ambiente SIG para integração de aplicação de instrumentos de gestão de recursos hídricos em bacias hidrográficas, com alto potencial de impacto socioeconômico e ambiental, a partir de uma adequada gestão do território. Este limite ainda é uma oportunidade a se explorar e tendo em vista que os estudos na UGRH Paranapanema foram pioneiros nesse contexto, outras UGRH ou bacias hidrográficas podem-se utilizar desses conhecimentos. 
Os modelos aqui apresentados podem ser mais bem elaborados nos Planos Integrado de Recursos Hídricos (PIRH) e subsidiar a elaboração da análise de proposta dos instrumentos de gestão de recursos hídricos como uma nova abordagem. Para atender os objetivos de estabelecer referências de avaliação de instrumento da gestão de recursos hídricos e considerar a visão integrada de processos físicos, químicos e biológicos ainda é um desafio conceitual, mesmo considerando a evolução tecnológica existente e a experiência adquirida desde a implementação da Lei 9.433/1997 ou Lei das Águas (Brasil, 1997).

Dessa forma, é importante a busca pelo entendimento das restrições ao uso da terra aqui indicadas e relações existentes entre as variáveis que interferem na proposição dos instrumentos de gestão de recursos hídricos, contribuindo assim para uma classificação mais eficiente e permitindo entender estes limites ambientais necessários neste contexto. Particularmente, a Resolução CONAMA № 357/2005 (Brasil, 2005) define o enquadramento como o estabelecimento de meta ou objetivo de qualidade da água (classe) a ser, obrigatoriamente, alcançado ou mantido em um segmento de corpo de água, de acordo com os usos preponderantes pretendidos, ao longo do tempo. Assim sendo, a identificação e definição do uso preponderante é uma das etapas fundamentais da proposição do enquadramento. Contudo, em bacias de usos múltiplos essa tarefa não é muito simples e pode ser ainda mais complexa, dependendo do porte e localização dela, razão pela qual a caracterização das restrições socioambientais ao uso da terra se faz necessária.

Atualmente as áreas restritivas que influenciam diretamente as classificações de enquadramento no Brasil são terras indígenas e Unidades de Conservação de Proteção Integral, portanto, este trabalho trouxe propostas de novas áreas que poderiam influenciar nessa classificação, tanto no acréscimo de novas áreas, ou ainda, áreas com mais de uma restrição socioambiental. Essas áreas restritivas se mostram áreas prioritárias para conservação, tendo em vista que emissões de cargas de poluentes nos rios se dão através de atividades antrópicas e, no presente trabalho, pela análise de uso da terra, notou-se que diversas áreas restritivas, que supostamente deveriam estar em seu estado natural, estão com usos antropizados.

\section{CONCLUSÕES}

O método empregado se mostrou eficiente na questão de representar de forma integrada os diferentes tipos de restrições socioambientais ao uso da terra, dentro de um mesmo recorte territorial como a URGH Paranapanema. Salienta-se a importância da qualidade dos dados espaciais para uma melhor representação cartográfica dos dados, no sentido que todos eles passaram por diversas etapas de edições (correção de Datum, topologia, entre outros). Mesmo tendo quinze diferentes camadas de restrições, é importante destacar que as áreas não recobertas por nenhuma delas podem ser áreas que ainda apresentam algum outro tipo de restrição, como no caso do estado do Paraná que dispõem de uma legislação para preservação das áreas úmidas remanescentes. Essas mesmas áreas com ausência de restrições podem ser ocupadas ainda por Reserva Legal, que não foram representadas neste trabalho, pois os dados contidos no Cadastro Ambiental Rural são declaratórios e devido à ausência de revisão/consistência não foram considerados na discussão. Pela extensão da área de estudo, algumas categorias se mostraram inviáveis de serem delimitadas, como no caso das APPs de Topo de Morro, na qual necessitam de métodos manuais de delimitação, tendo em vista sua complexidade de sua execução que necessita de interpretações geomorfológicas.

Foi observado um alto estado de antropização ao longo da área de estudo, tendo aproximadamente $80 \%$ do território ocupado por algum uso agropecuário. Esse percentual foi observado também na categoria de APP de nascente, que são áreas importantes no que tange a questão de recursos hídricos. Em relação às Unidades de Conservação foi observado que as de Uso Sustentável apresentam um elevado percentual de áreas com uso antrópico, destacando-se o alto grau de degradação das APP, diferentemente das de Proteção Integral que apresentam quase 90\% em seu estado natural.

A análise integrada das restrições socioambientais denota elevado potencial para subsidiar o enquadramento de corpos hídricos, avaliação de outorgas, ou ainda, licenciamento ambiental. No caso do enquadramento, este revela-se como instrumento de Gestão Ambiental do Território com potencial de que seja integrado, por exemplo a um Zoneamento Ecológico-Econômico (ZEE), Planos Diretores Municiais (PDM), Planos Municipais da Mata Atlântica (PMMA), Planos Municipais de Saneamento Básico, entre outros. Ainda cabe destacar que outra possibilidade de uso destes resultados no âmbito 
de outorgas, refere-se ao apoio à avaliação das demandas de renovação, ampliação ou até mesmo consolidação de novas.

Os resultados apresentados neste artigo, além de contribuir para uma integração entre a gestão ambiental e dos recursos hídricos, abordam uma metodologia que relaciona diferentes dimensões (ambiental, social, cultural), e que inclusive pode contribuir para a formulação e implementação dos instrumentos de gestão, como por exemplo, os Planos de Recursos Hídricos. A metodologia aplicada forneceu um diagnóstico ambiental sobre a UGRH Paranapanema, na qual pode ser replicada para outras UGRH, como também abre espaço para novas discussões e outras categorias de análise, que podem ser incluídas em futuros trabalhos.

\section{AGRADECIMENTOS}

À Agência Nacional de Águas (ANA), aos programas de pós-graduação em Geografia, Ciências Geodésicas e em Engenharia de Recursos Hídricos e Ambiental da Universidade Federal do Paraná (UFPR), e ao Laboratório de Geoprocessamento e Estudos Ambientais (LAGEAMB) do Departamento de Geografia da UFPR. Cristovão Fernandes agradece o apoio da bolsa de produtividade do Conselho Nacional de Pesquisa.

\section{REFERENCIAS BIBLIOGRÁFICAS}

Agência Nacional de Águas - ANA. (2010). Abastecimento Urbano de Água: Panorama nacional. Brasília: Engecorps/Cobrape.

Almeida, A. M., Paula, E. V., \& Isaguirre, K. R. (2016). A Lei Florestal Brasileira (Lei nº 12.651/12 e a Problemática dos Parâmetros, Definições e Limites das Áreas de Preservação Permanente de Topo de Morros, Montes, Montanhas e Serras. In Anais do $21^{\circ}$ Congresso Brasileiro de Direito Ambiental, Anais do $11^{\circ}$ Congresso de Direito Ambiental nos Países de Língua Portuguesa e Espanhola, Anais do $11^{\circ}$ Congresso de Estudantes de Direito Ambiental, São Paulo (pp. 366-379). São Paulo: Instituto Planeta Verde.

Amorim, R. A., \& Oliveira, R. C. (2013). Zoneamento ambiental, subsídio ao planejamento no uso e ocupação das terras da costa do descobrimento. Mercator (Fortaleza), 12(29), 211-231.

Bitencourt, C. C. A., Fernandes, C. V. S., \& Gallego, C. E. C. (2019). Panorama do enquadramento no Brasil: uma reflexão crítica. Revista de Gestão de Água da América Latina, 16, e9.

Brasil. (1981, 31 de Agosto). Lei no 6.938, de 31 de agosto de 1981. Dispõe sobre a Política Nacional do Meio Ambiente, seus fins e mecanismos de formulação e aplicação, e dá outras providências. Diário Oficial da União. Brasília, DF, 31 de agosto de 1981. Recuperado em 5 de outubro de 2020, de http://www.planalto.gov.br/ccivil_03/leis/16938.htm

Brasil. (1997). Ministério do Meio Ambiente dos Recursos Hídricos e da Amazônia Legal. Lei n. 9.433 de 8 de janeiro de 1997. Política Nacional de Recursos Hídricos. Brasília: Secretaria de Recursos Hídricos. Recuperado em 25 de abril de 2021, de http://www.planalto.gov.br/ccivil_03/leis/19433.htm

Brasil. (2000). Lei no 9.985, de 18 de julho de 2000. Regulamenta o art. 225, § 1o, incisos I, II, III e VII da Constituição Federal, institui o Sistema Nacional de Unidades de Conservação da Natureza e dá outras providências. Diário Oficial da União. Brasília, DF, 18 de julho de 2000. Diário Oficial [da] República Federativa do Brasil, Brasília. Recuperado em 5 de outubro de 2020, de http://www.planalto.gov.br/ccivil_03/leis/19985.htm

Brasil. (2002, 20 de Março). Resolução CONAMA n 302 de 20 de março de 2002. Dispõe sobre os parâmetros, definições e limites de Áreas de Preservação Permanente de reservatórios artificiais e o regime de uso do entorno. Diário Oficial [da] República Federativa do Brasil, Brasília. Recuperado em 12 de janeiro de 2021, de https://www.legisweb.com.br/legislacao/?id=98315

Brasil. Conselho Nacional de Meio Ambiente - CONAMA. (2005). Resolução no 357, de 17 de março de 2005. Dispõe sobre a classificação dos corpos de água e diretrizes ambientais para o seu enquadramento, bem como estabelece as condições e padrões de lançamento de efluentes, e dá outras providências. Diário Oficial [da] República Federativa do Brasil, Brasília. Recuperado em 5 de abril de 2020, de http://www.mma.gov.br/port/conama/res/res05/res35705.pdf</eref>

Brasil. (2004a, 21 de maio). Decreto ${ }^{\circ}$ 5.092, de 21 de maio de 2004. Define regras para identificação de áreas prioritárias para a conservação, utilização sustentável e repartição dos benefícios da biodiversidade, no âmbito das atribuições do Ministério do Meio Ambiente. Diário Oficial [da] 
República Federativa do Brasil, Brasília. Recuperado em 3 de setembro de 2021, de http://www.planalto.gov.br/ccivil_03/_ato2004-2006/2004/decreto/d5092.htm

Brasil. (2004b, 19 de abril). Decreto ${ }^{\circ}$ 5.051, de 19 de abril de 2004. Promulga a Convenção no 169 da Organização Internacional do Trabalho - OIT sobre Povos Indígenas e Tribais. Diário Oficial [da] República Federativa do Brasil, Brasília. Recuperado em 3 de setembro de 2021, de http://www.planalto.gov.br/ccivil_03/_ato2004-2006/2004/decreto/d5051.htm

Brasil. (2012, 25 de maio). Lei no 12.651, de 25 de maio de 2012. Novo Código Florestal. Dispõe sobre a proteção da vegetação nativa; altera as Leis no 6.938, de 31 de agosto de 1981, 9.393, de 19 de dezembro de 1996, e 11.428, de 22 de dezembro de 2006; revoga as Leis no 4.771, de 15 de setembro de 1965, e 7.754, de 14 de abril de 1989, e a Medida Provisória no 2.166-67, de 24 de agosto de 2001; e dá outras providências. Diário Oficial [da] República Federativa do Brasil, Brasília. Diário Oficial [da] República Federativa do Brasil, Brasília. Recuperado em 5 de outubro de 2020, de http://www.planalto.gov.br/ccivil_03/_ato2011-2014/2012/lei/l12651.htm

Brasil. Ministério do Desenvolvimento Agrário. Instituto Nacional de Colonização e Reforma Agrária, Diretoria de Gestão Administrativa. (2008, 12 de março). Norma de execução n 69, de 12 de março de 2008. Dispõe sobre o processo de criação e reconhecimento de projetos de assentamento de Reforma Agrária. Diário Oficial [da] República Federativa do Brasil, Brasília. Recuperado em 3 de setembro de 2021, de https://antigo.incra.gov.br/media/docs/legislacao/norma-execucao/ne_692008_proc_criacao_e_reconh_pas.pdf

Brasil. Ministério do Meio Ambiente. (2018). Áreas Prioritárias para Conservação da Biodiversidade Brasileira. Brasília. Recuperado em 28 de agosto de 2019, de http://areasprioritarias.mma.gov.br/2atualizacao-das-areas-prioritarias

Fundação Nacional do Índio - FUNAI. (2019). Modalidades de terras indígenas. Brasília. Recuperado em 8 de maio de 2021, de http://www.funai.gov.br/index.php/indios-no-brasil/terras-indigenas

Grupo Integrado de Aquicultura e Estudos Ambientais - GIA. (2013). Estudos para a definição dos parques aquícolas nos reservatórios do Paranapanema (Vol. 2: Parâmetros abióticos e modelagem). Ministério da Pesca e Aquicultura.

Gudiño, M. E. (2016). El Ordenamiento Territorial en América Latina ¿Ilusión o realidad? Desafíos para el siglo XXI [Territorial Planning in Latina America Illusion or reality? Challenges for the 21st century]. In M. Queirós (Coord.). O desafio do planeamento e observação territorial nos países Ibero-americanos para o século XXI: dinâmicas, processos, experiências e propostas [O challenge of territorial planning and observation in the Ibero-American countries for the 21st century: dynamics, processes, experiences and proposals] (pp. 17-36). Lisboa: Centro de Estudos Geográficos, Instituto de Geografia e Ordenamento do Território, Universidade de Lisboa.

Instituto Ambiental do Paraná - IAP. (2004, Junho). Plano de Manejo: Área de Proteção Ambiental da Escarpa Devoniana. Recuperado em 12 de janeiro de 2021, de http://www.iat.pr.gov.br/sites/aguaterra/arquivos_restritos/files/documento/2020-07/apa_escarpa_devoniana_1_apa_pm.pdf

Instituto Brasileiro de Geografia e Estatística - IBGE. (2013). Manual técnico de uso da terra (3. ed.). Rio de Janeiro: IBGE.

Instituto Nacional de Colonização e Reforma Agrária - INCRA. (2020). Assentamentos. Brasília. Recuperado em 27 de agosto de 2020, de http://www.incra.gov.br/pt/assentamentos.html

Laboratório de Geoprocessamento e Estudos Ambientais - LAGEAMB. (2020). Nota técnica LAGEAMB 2020: Base de Dados Geoespaciais e Gestão Documental de Projetos (54 p.). Curitiba: Universidade Federal do Paraná.

Massiris Cabeza, A. (2012). Gestión territorial y desarrollo. Hacia una política de desarrollo territorial sostenible en América Latina [Territorial management and development. Towards a sustainable territorial development policy in Latin America]. Tunja: Universidad Pedagógica y Tecnológica de Colombia.

Miranda, G. M. (2020). Motivações e desafios para a implementação da gestão integrada de recursos hídricos em federações: os casos brasileiro e suíço. Revista de Gestão de Água da América Latina, 17, e6.

Nowatzki, A. (2019). Mapeamento Pedológico Preditivo por Diferentes Métodos de Integrações de Atributos Topográficos: Aplicações No Baixo Curso da Bacia Hidrográfica do Rio Ivaí - Noroeste do Estado do Paraná (Tese de doutorado). Curitiba: Universidade Federal do Paraná.

Nowatzki, A., Jarentchuk Junior, O., \& Paula, E. V. (2016). O contexto geográfico e ambiental das Áreas de Preservação Permanente. Terr@ Plural (UEPG. Online), 10, 23-34. 
Nowatzki, A., Santos, L. J. C., \& Paula, E. V. (2010). Utilização do SIG na Delimitação das Áreas de Preservação Permanente (APP'S) na Bacia Do Rio Sagrado (Morretes/Pr). Sociedade \& Natureza (UFU. Online), 22, 121-134.

Paraná. (2007). Decreto 1529 - 2 de outubro de 2007. Dispõe sobre o Estatuto Estadual de Apoio à Conservação da Biodiversidade em Terras Privadas no Estado do Paraná, atualiza procedimentos para a criação de Reservas Particulares do Patrimônio Natural - RPPN - e dá outras providências. Diário Oficial do Estado, Curitiba. Recuperado em 9 de abril de 2021, de https://www.legislacao.pr.gov.br/legislacao/pesquisarAto.do?action=exibir\&codAto=50391\&indice= 1\&totalRegistros $=7$

Paraná. (2008). Resolução Conjunta IBAMA/SEMA/IAP N 005, de 28 de março de 2008. Define critérios para avaliação das áreas úmidas e seus entornos protetivos, normatiza sua conservação e estabelece condicionantes para o licenciamento das atividades nelas permissíveis no Estado do Paraná. Diário Oficial do Estado, Curitiba. Recuperado em 12 de janeiro de 2021, de https://ambienteduran.eng.br/publicador/LEGISLACAO/ESTADUAL/RESOLUCAO_CONJUNTA_IBAMA_ SEMA_IAP_005_2008.pdf

Paraná (1953). Lei no 1.211, de 18 de setembro de 1953. Dispõe sobre o patrimônio histórico, artístico e natural do Estado do Paraná. Diário Oficial do Estado. Curitiba, Recuperado em 3 de setembro de 2021, de https://www.legislacao.pr.gov.br/legislacao/pesquisarAto.do?action=exibir\&codAto=14834\&indice=1\&tot alRegistros $=1 \& \mathrm{dt}=3.8 .2021 .9 .28 .12 .975$

Paraná. (2014a). Lei Complementar no 170, de 31 de março de 2014. Dispõe sobre a repartição do ICMS, a que alude o art. $2^{\circ}$ da Lei no 9.491, de 21 de dezembro de 1990, aos municípios com mananciais de abastecimento e unidades de conservação ambiental. Diário Oficial do Estado, Curitiba. Recuperado em 12 de janeiro de 2021, de

https://www.legislacao.pr.gov.br/legislacao/listarAtosAno.do?action=exibir\&codAto=116538\&codTip oAto $=3 \&$ tipoVisualizacao $=$ original

Paraná (2014b). Lei complementar no 170, de 31 de março de 2014. Altera a Lei Complementar no 59, de 1o de outubro de 1991. Diário Oficial do Estado. Curitiba, Recuperado em 3 de setembro de 2021, de https://www.legislacao.pr.gov.br/legislacao/pesquisarAto.do?action=exibir\&codAto=116538\&indice=1\&t otalRegistros=1\&dt=3.8.2021.9.31.6.612

Paraná. Secretaria de Estado da Cultura - SEEC. (2021). Patrimônio Cultural. Curitiba, Paraná. Recuperado em 12 de janeiro de 2021, de http://www.patrimoniocultural.pr.gov.br

Paz, O. L. S., Dal Pai, M. O., \& Paula, E. V. (2020). Proposta metodológica para elaboração de base de dados geoespaciais como subsídio a estudos ambientais: aplicação em unidades de conservação do litoral norte do Paraná. Revista Brasileira de Geografia Física, 13(2), 613-629. Recuperado em 8 de maio de 2021, de <https://periodicos.ufpe.br/revistas/rbgfe/article/view/242899/34858

Plano Integrado de Recursos Hídricos - PIRH. (2006). Unidade de Gestão de Recursos Hídricos Paranapanema (PIRH Paranapanema) (335 p.). Brasília. Recuperado em 9 de maio de 2021, de https://www2.paranapanema.org/plano-de-bacia/

Sampaio, T. V. M., \& Brandalize, M. C. B. (2018). Cartografia Geral, Digital e Temática - Geotecnologias: Teoria e Práticas. Curitiba: Programa de Pós-graduação em Ciências Geodésicas - UFPR. Recuperado em 9 de abril de 2020, de http://www.prppg.ufpr.br/site/ppggeografia/wpcontent/uploads/sites/71/2018/03/cartografia-geral-digital-e-tematica-b.pdf

Santos, R. F. (2004). Planejamento ambiental: teoria e prática (184 p.). São Paulo: Oficina de Textos.

Silva, J. S. V., \& Santos, R. F. (2011). Estratégia metodológica para zoneamento ambiental: a experiência aplicada na Bacia Hidrográfica do Alto Rio Taquari. Campinas: Embrapa Informática Agropecuária. Recuperado em 5 de outubro de 2020, de https://www.embrapa.br/busca-de-publicacoes//publicacao/913452/estrategia metodologica-para-zoneamento-ambiental-a-experiencia-aplicada-nabacia-hidrografica-do-alto-rio-taquari

Silva, L. S., \& Paula, E. V. (2020, Julho). El Análisis Espacial de las Restricciones Legales al Uso de la Tierra: Contribuciones a la Planificación y Gestión del Territorio en Brasil. Revista Proyección, 12(27), 57-79. 
Jhenifer Priscila Borges do Couto: Contribuiu na geração e edição de dados geoespaciais e escrita do artigo.

Eduardo Vedor de Paula: Contribuiu no desenvolvimento e aplicação do método, análise dos dados e escrita do artigo.

Cristovão Vicente Scapulatempo Fernandes:

Contribuiu na idealização do trabalho, análise dos dados e escrita do artigo. 